\title{
In Vitro and in Vivo Evaluation of Membrane- Active Flavone Amphiphiles: Semisynthetic Kaempferol-Derived Antimicrobials against Drug-Resistant Gram-Positive Bacteria
}

Shuimu Lin, ${ }^{\dagger}$ Hongxia Li, ${ }^{\dagger}$ Yiwen Tao, ${ }^{\dagger}$ Jiayong Liu, ${ }^{\dagger}$ Wenchang Yuan, ${ }^{\dagger}$ Yongzhi Chen, ${ }^{\dagger}$ Ying Liu, $₫$ Shouping Liu* ${ }^{*} \uparrow$

†ey Laboratory of Molecular Target \& Clinical Pharmacology and the State Key Laboratory of Respiratory Disease, School of Pharmaceutical Sciences \& the Fifth Affiliated Hospital, Guangzhou Medical University, Guangzhou 511436, P.R. China Guangdong Key Laboratory of Optical Fiber Sensing and Communications, Institute of Photonics Technology, Jinan University, Guangzhou, Guangdong 510632, P.R. China

* Corresponding Author. Email address: liushouping2018@163.com 


\section{Table of Contents}

1. Table S1. MIC values of amphiphilic kaempferol derivatives against various Gram-negative bacterial strains

2. Figure S1. Fluorescence changes of compounds $\mathbf{4 5}$ and $\mathbf{5 2}$ without adding

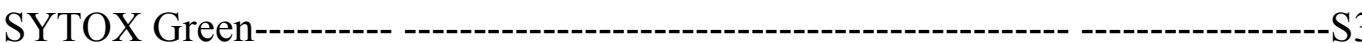

3. Water solubility test

S4

4. HPLC traces of the final kaempferol compounds -S5 
Table S1. MIC values of amphiphilic kaempferol derivatives against various Gramnegative bacterial strains.

\begin{tabular}{lllll}
\hline & \multicolumn{4}{c}{ MIC, $\mu \mathrm{g} / \mathrm{mL}(\mu \mathrm{M})$} \\
\cline { 2 - 5 } Compd & $\begin{array}{l}\text { E. coli } \\
\text { ATCC25922 }\end{array}$ & $\begin{array}{l}\text { P. aeruginosa } \\
\text { ATCC9027 }\end{array}$ & $\begin{array}{l}\text { P. aeruginosa } \\
\text { isolate 01 }\end{array}$ & $\begin{array}{l}\text { P. aeruginosa } \\
\text { isolate 02 }\end{array}$ \\
\hline $\mathbf{4 5}$ & $>50(>76.8)$ & $>50(>76.8)$ & $>50(>76.8)$ & $>50(>76.8)$ \\
$\mathbf{5 2}$ & $12.5(14.2)$ & $25(28.4)$ & $25(28.4)$ & $25(28.4)$ \\
\hline
\end{tabular}

Figure S1. Fluorescence changes of compounds $\mathbf{4 5}$ and $\mathbf{5 2}$ at different concentrations $(1 \times, 2 \times, 4 \times$ and $8 \times$ MIC) in the presence of (A) PBS, (B) S. aureus ATCC29213 and (C) MRSA NCTC10442 without adding SYTOX Green.
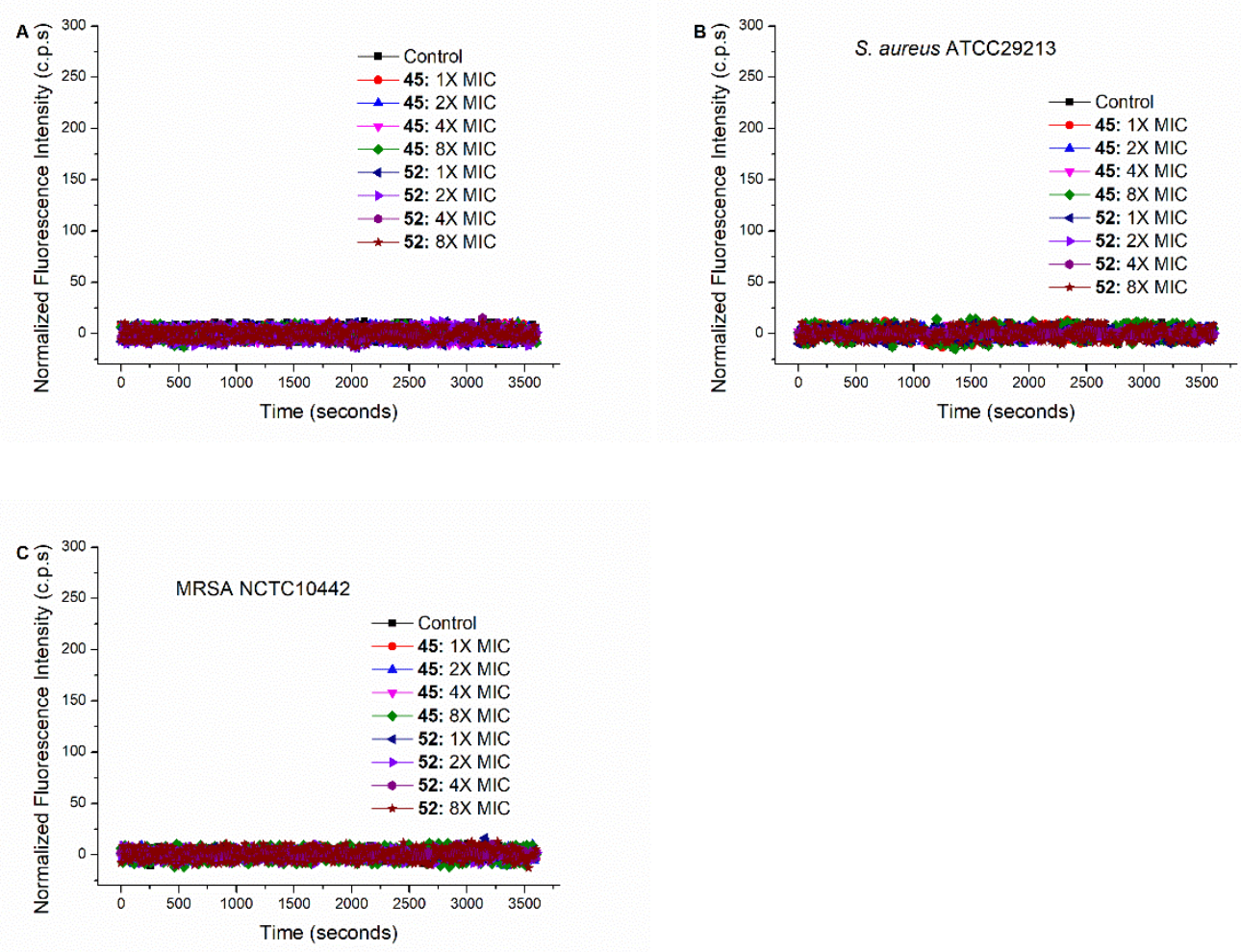


\section{Water Solubility Test.}

$150 \mu \mathrm{L}$ of water was added to $2 \mathrm{mg}$ of compound $\mathbf{5 2}$. Compound $\mathbf{5 2}$ was completely dissolved, which was visually observed as a clear solution. Its absorbance at $540 \mathrm{~nm}$ was measured to be the same as that of water. The result indicated that the solubility of compound $\mathbf{5 2}$ in water was greater than $13.3 \mathrm{mg} / \mathrm{mL}$. 
HPLC traces of the final kaempferol compounds

HPLC trace of $\mathbf{1 1}$

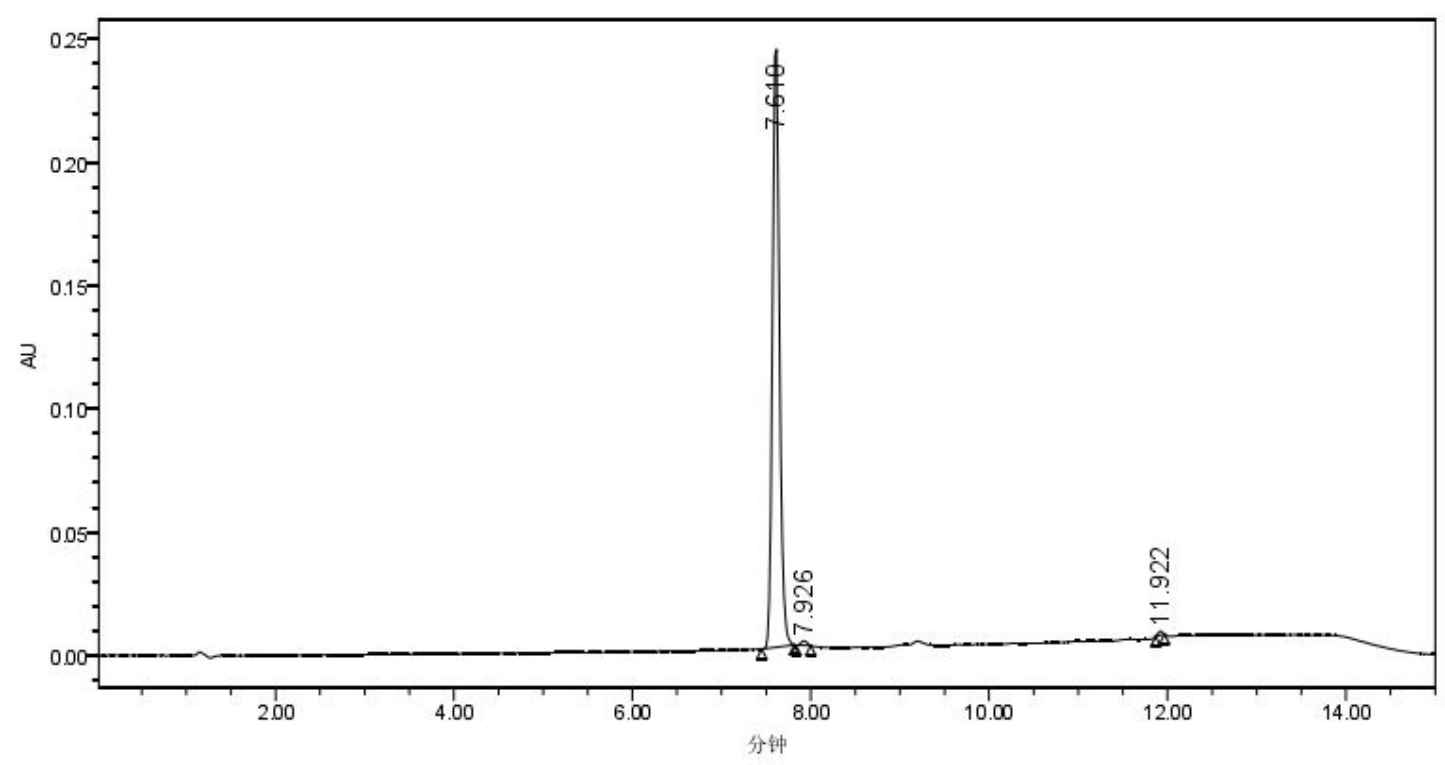

HPLC trace of $\mathbf{1 2}$

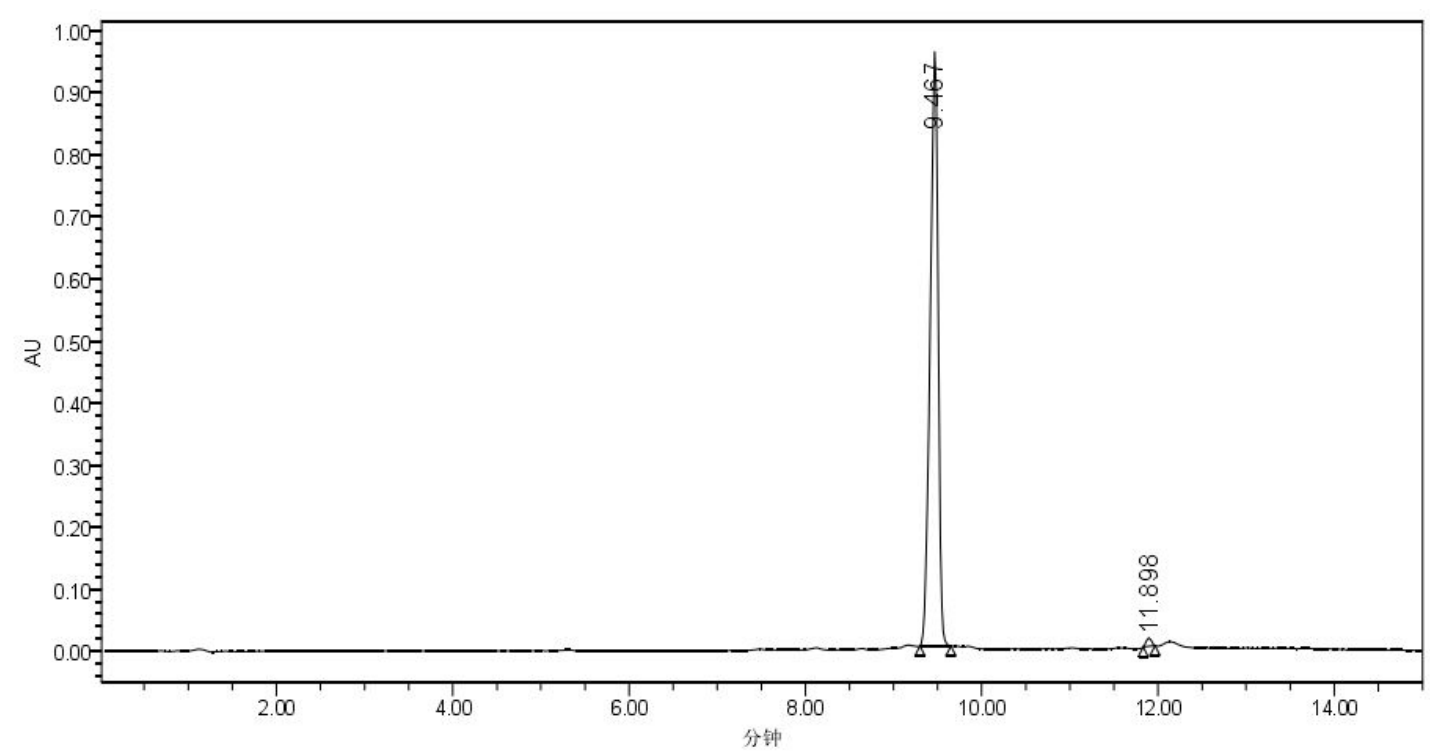


HPLC trace of $\mathbf{1 3}$

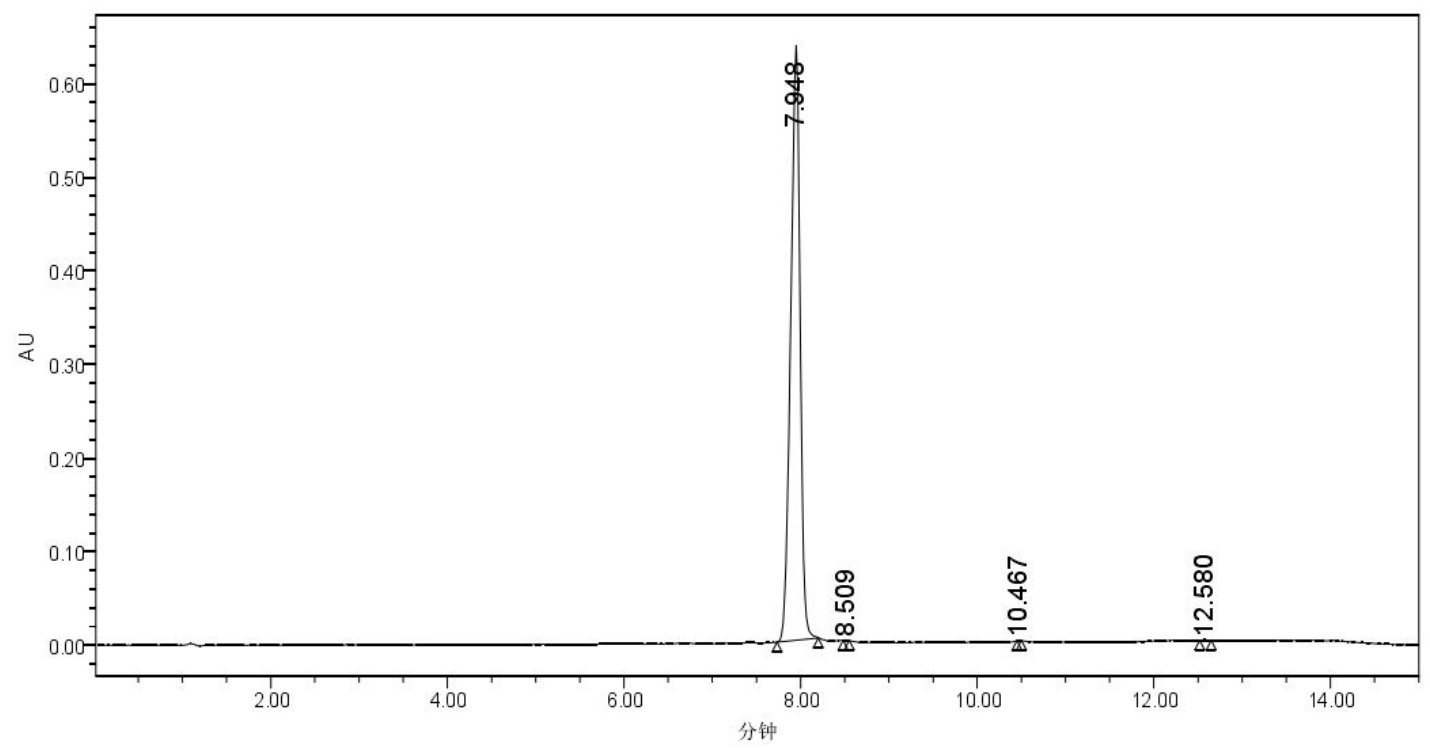

HPLC trace of 14

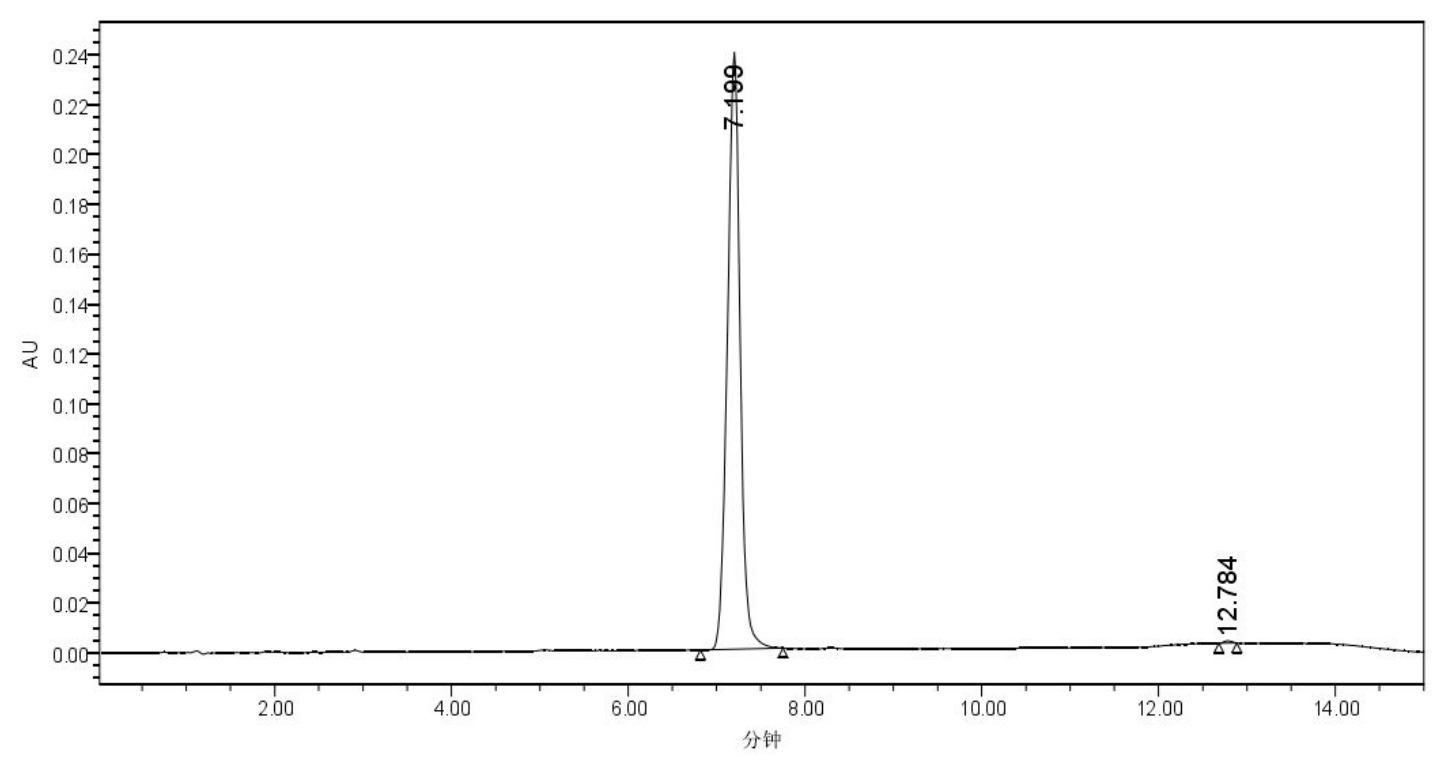


HPLC trace of $\mathbf{1 5}$

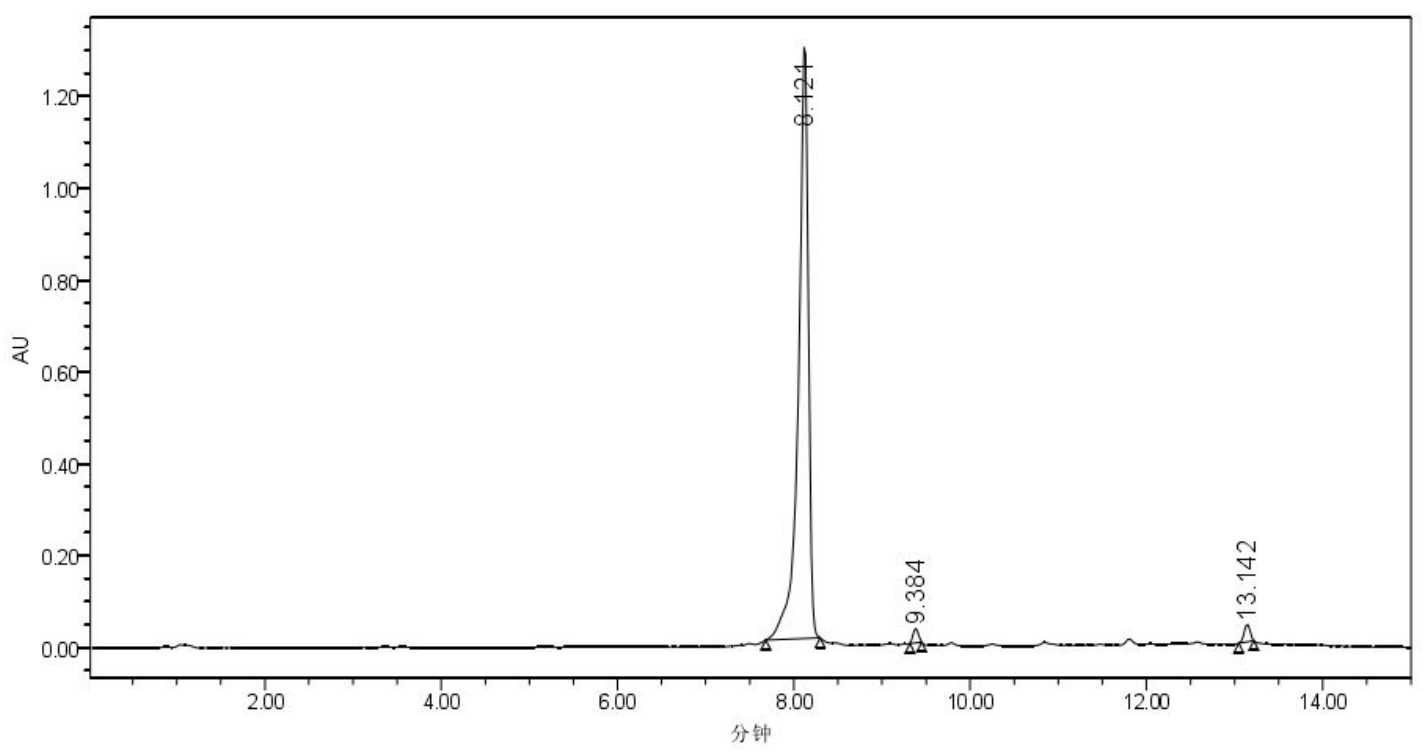

HPLC trace of 22

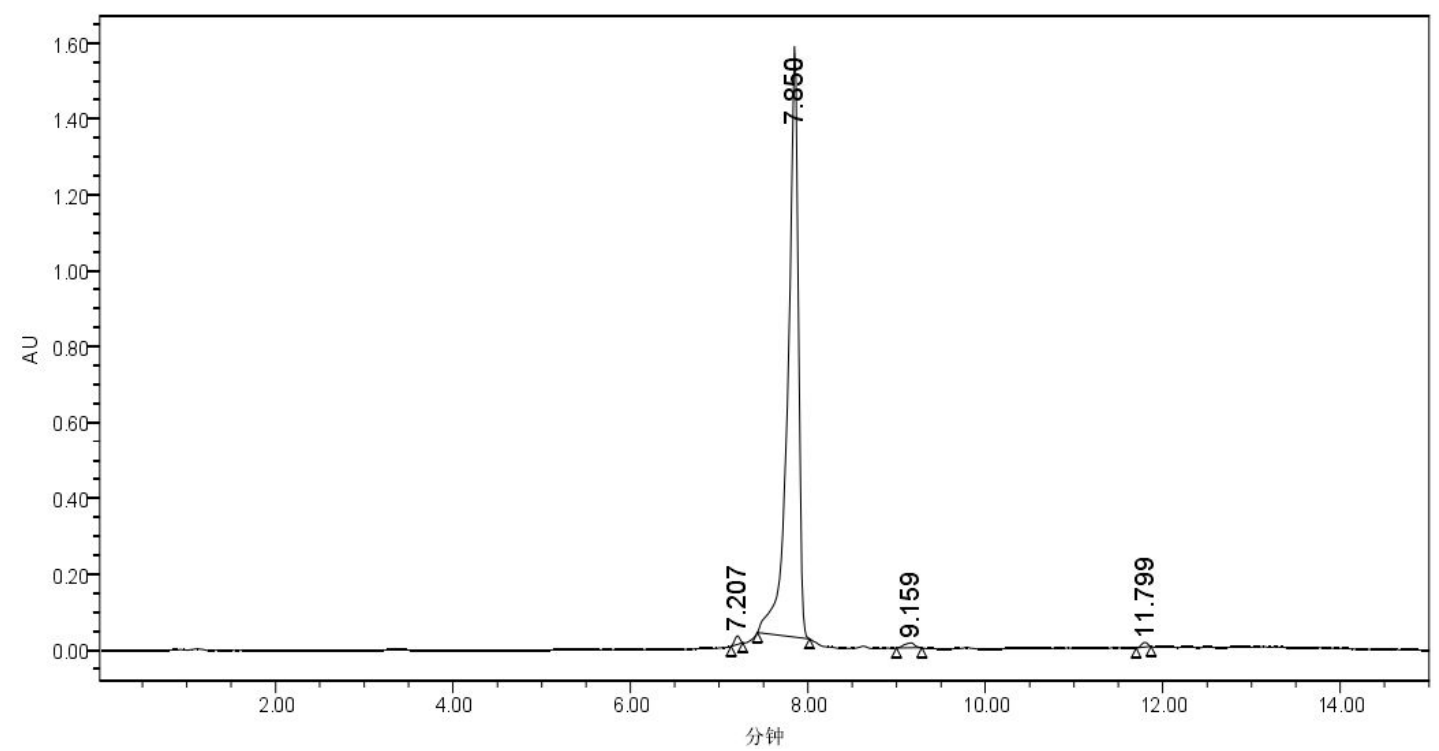


HPLC trace of $\mathbf{2 3}$

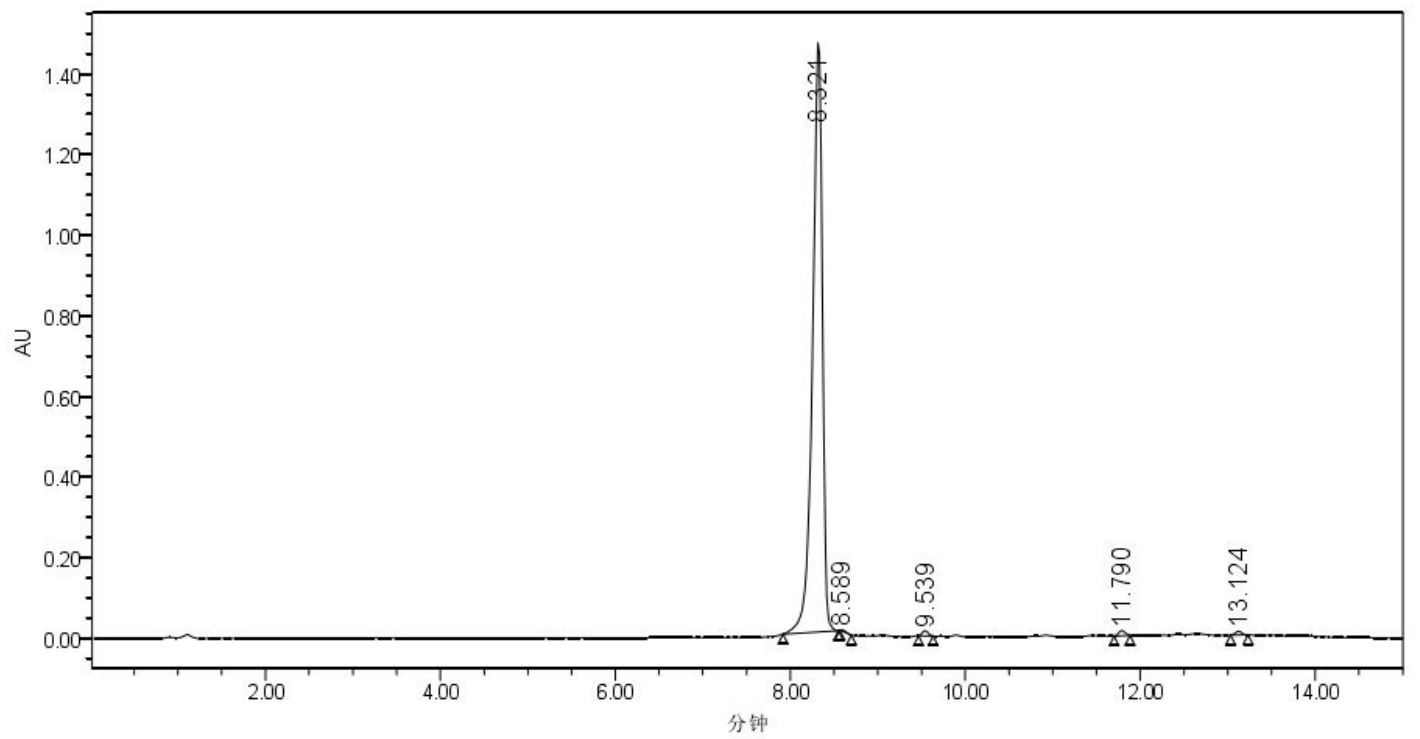

HPLC trace of $\mathbf{2 4}$

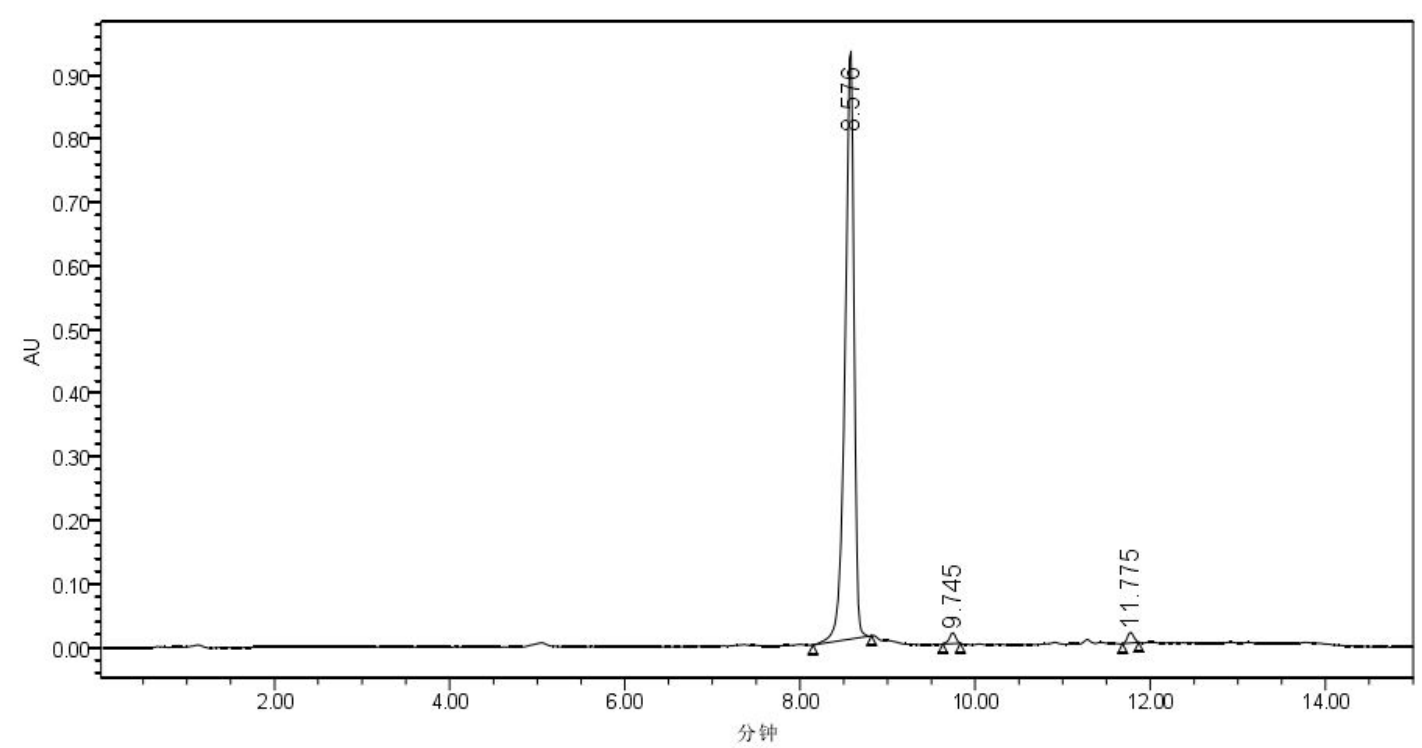


HPLC trace of $\mathbf{2 5}$

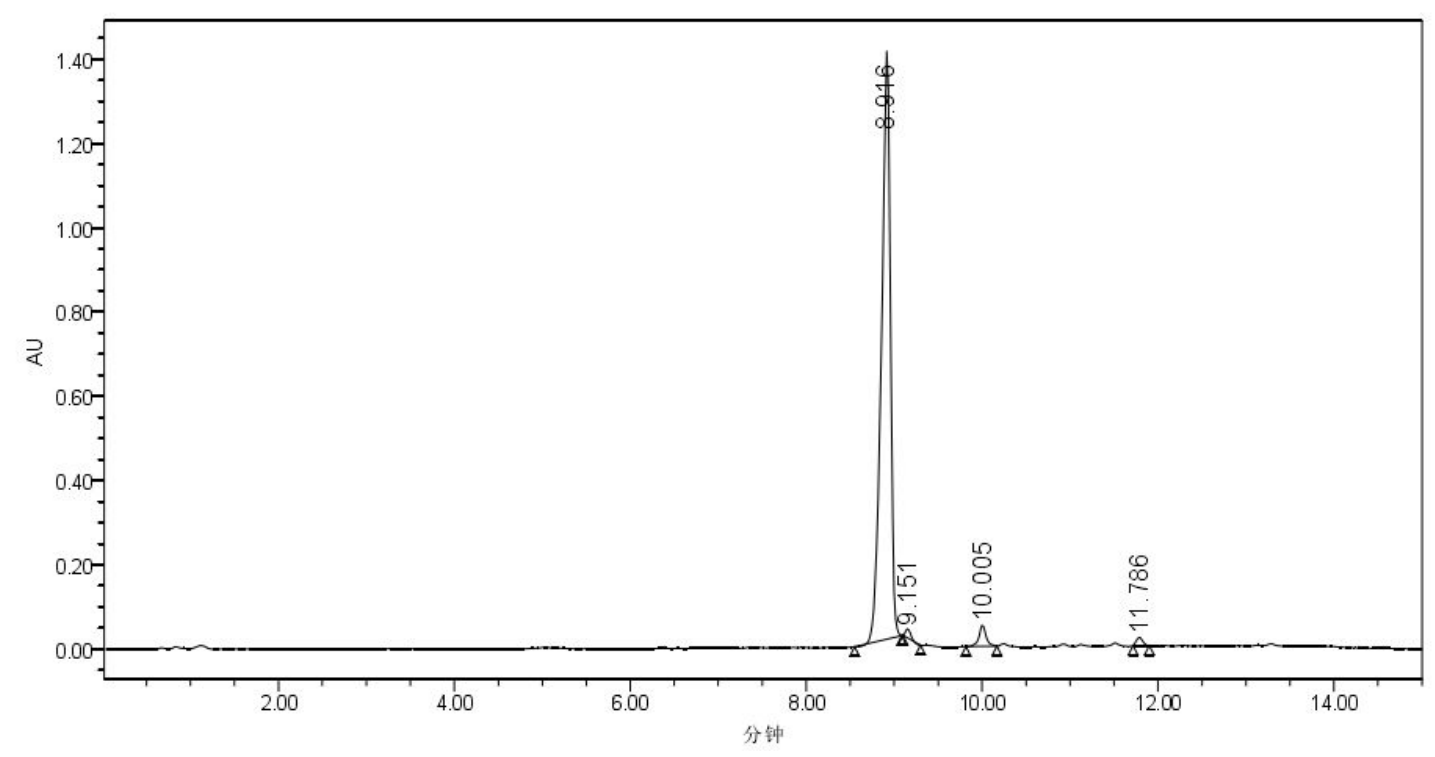

HPLC trace of $\mathbf{2 6}$

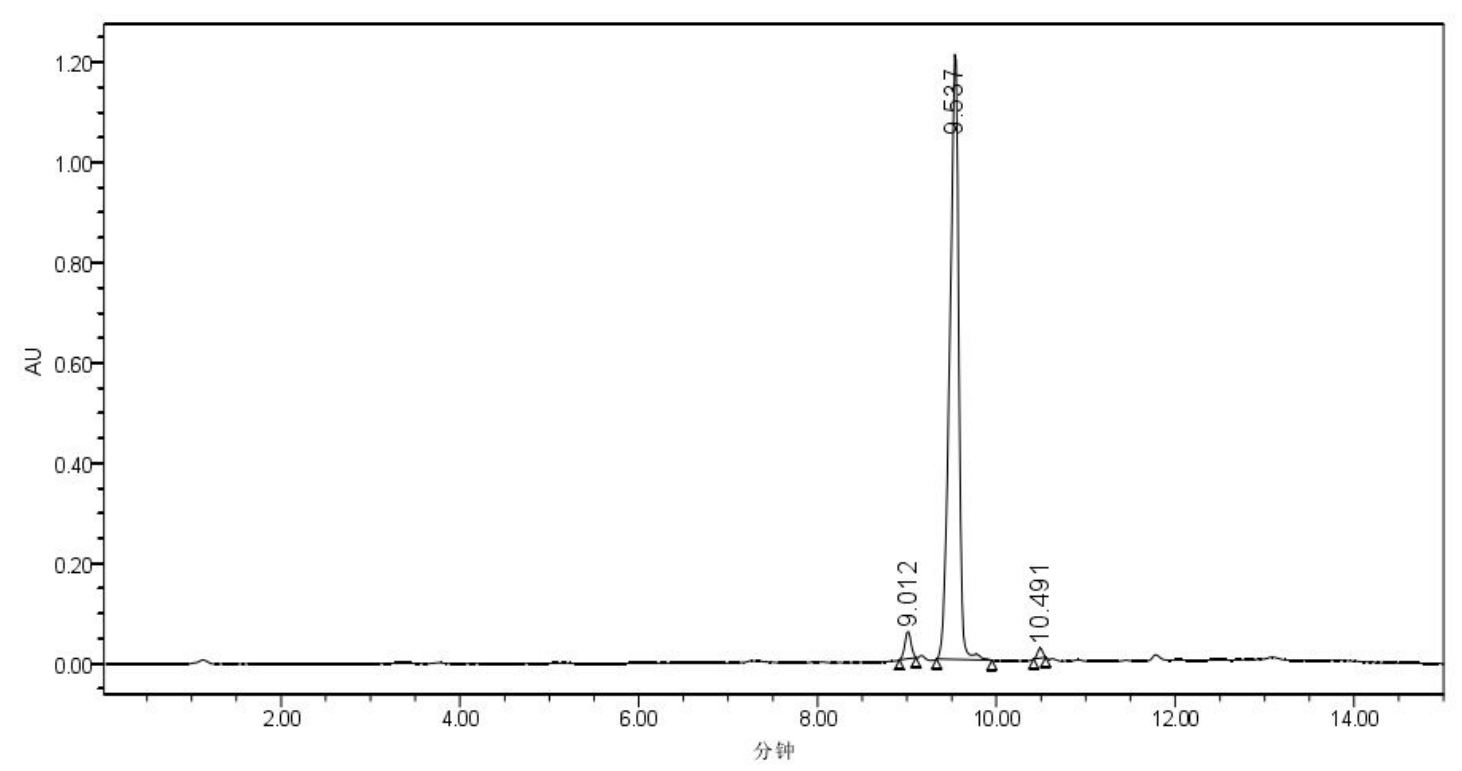


HPLC trace of 27

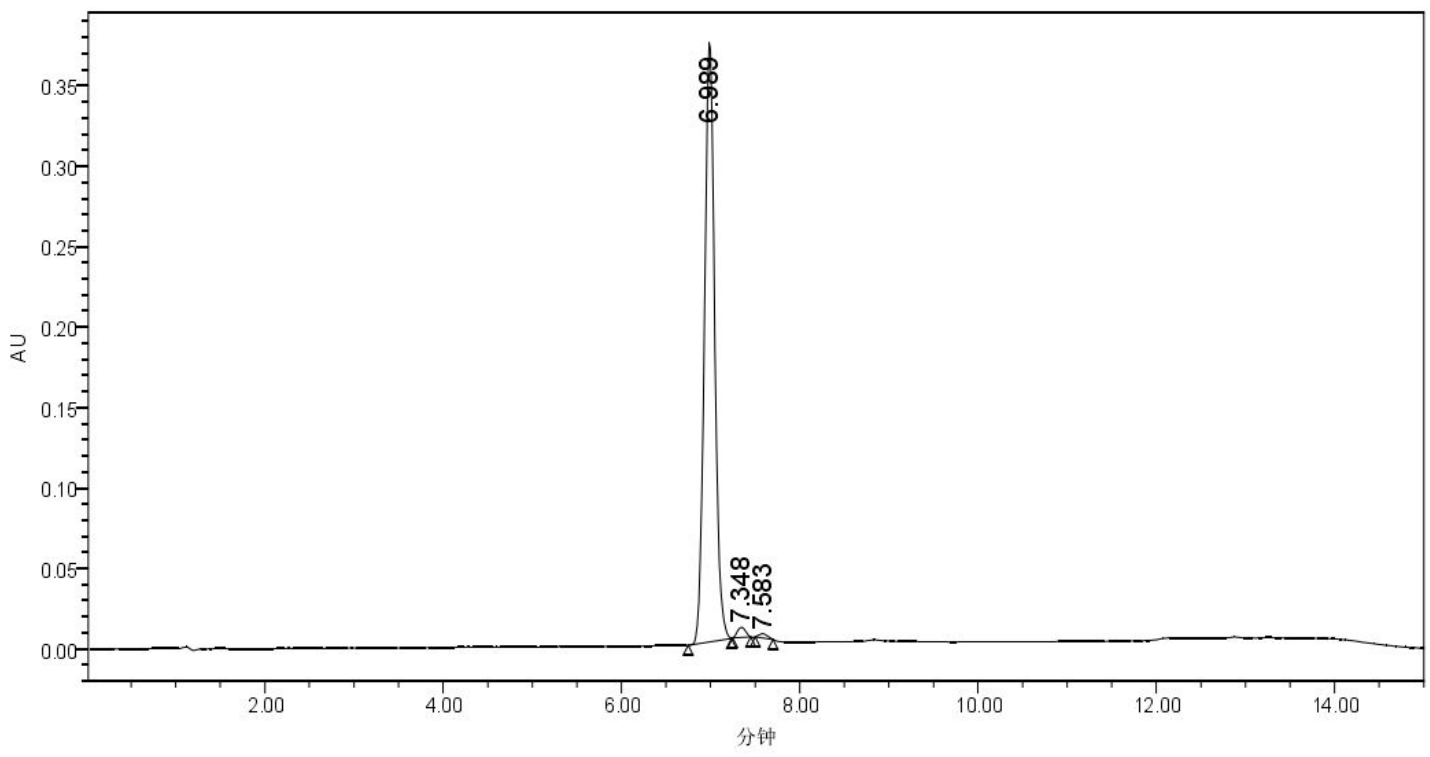

HPLC trace of $\mathbf{2 8}$

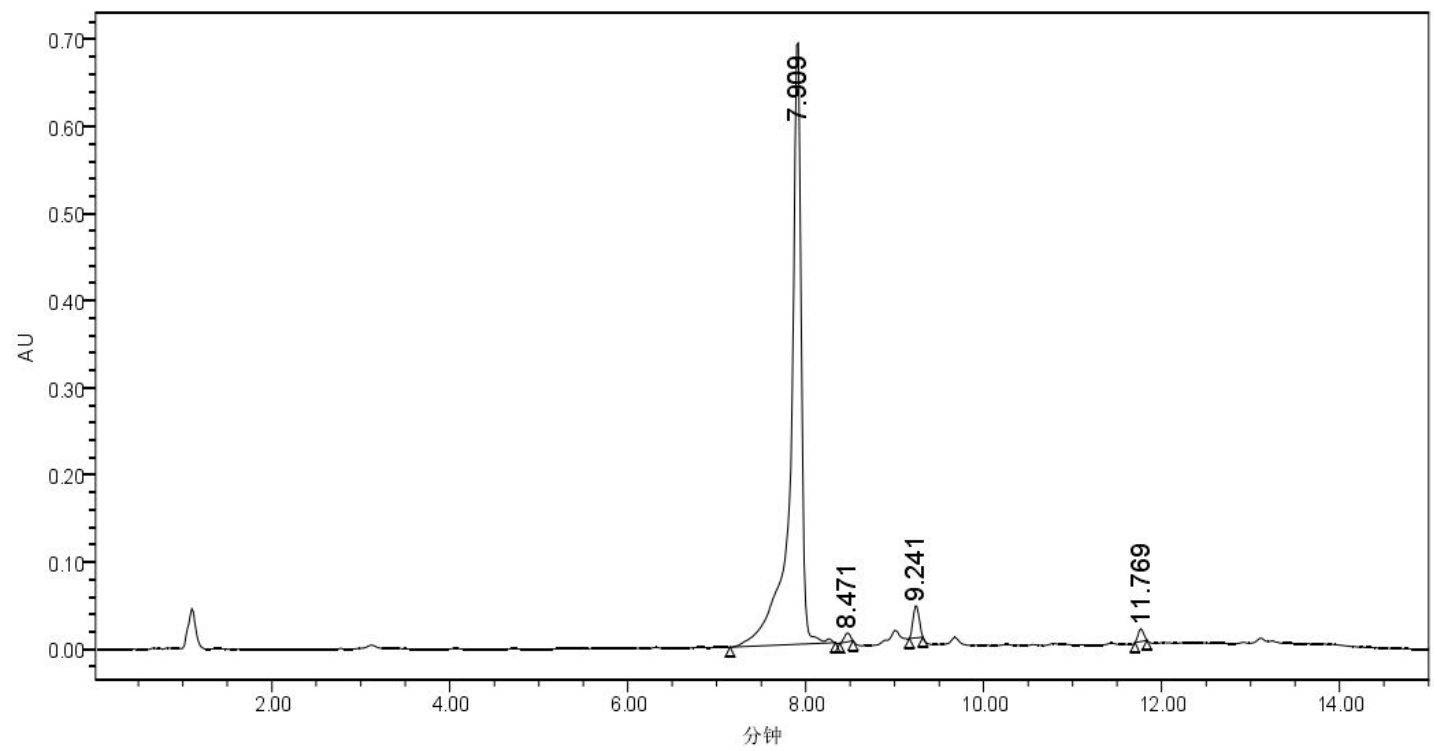


HPLC trace of $\mathbf{2 9}$

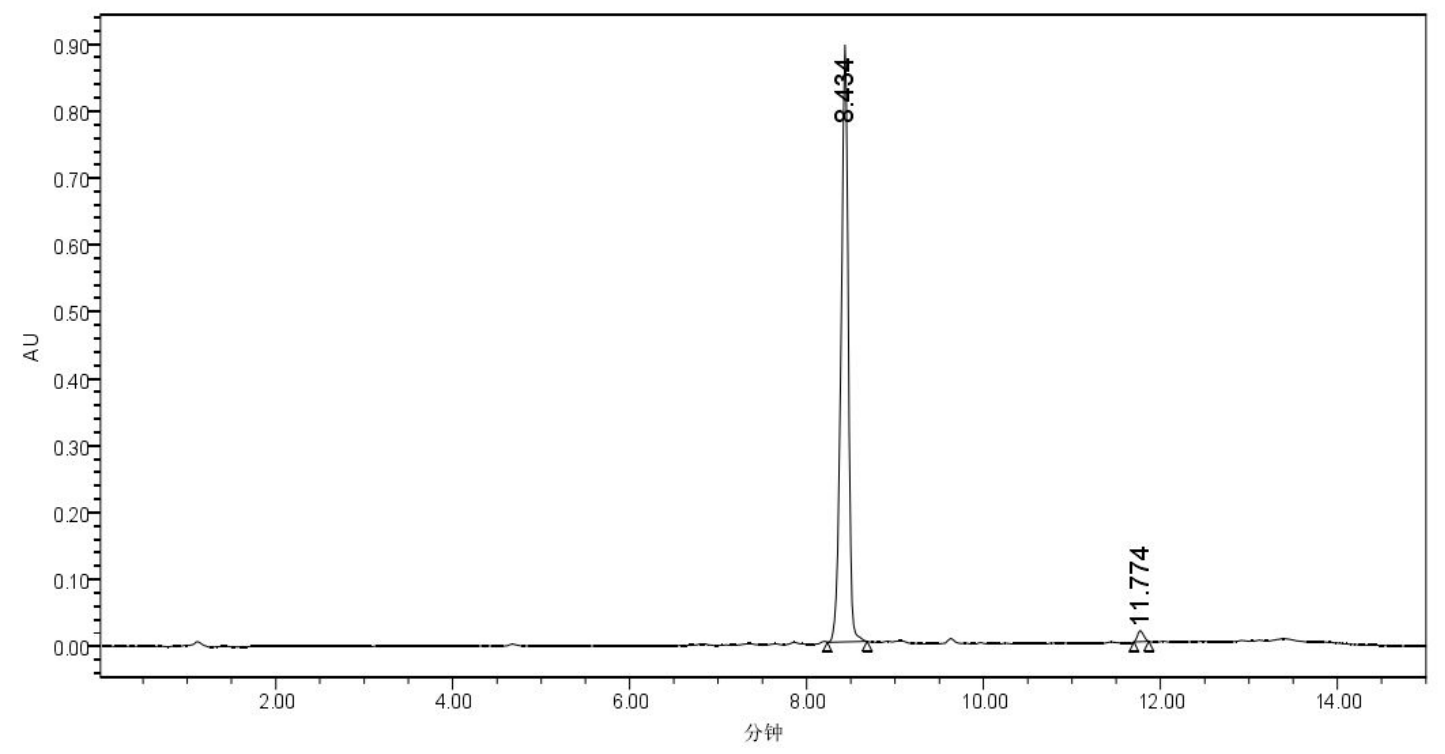

HPLC trace of $\mathbf{3 0}$

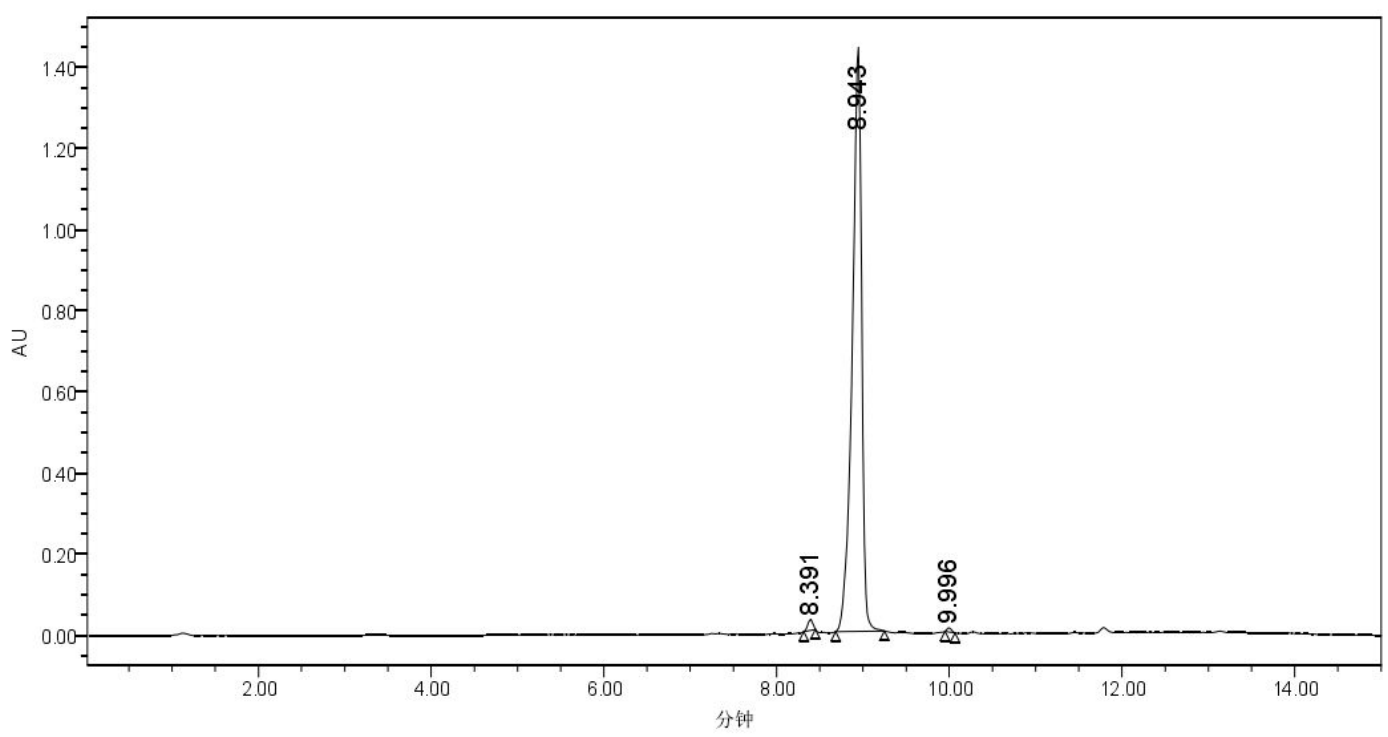


HPLC trace of $\mathbf{3 1}$

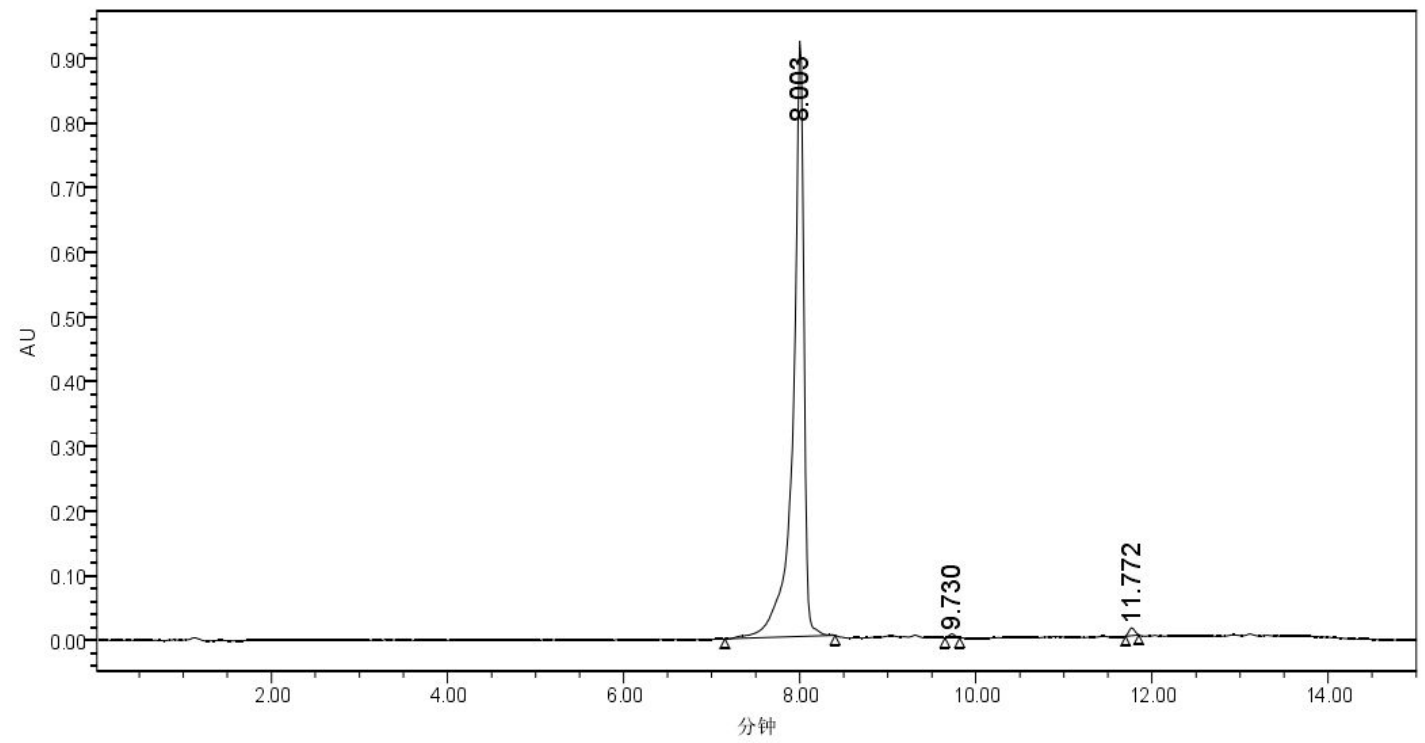

HPLC trace of $\mathbf{3 2}$

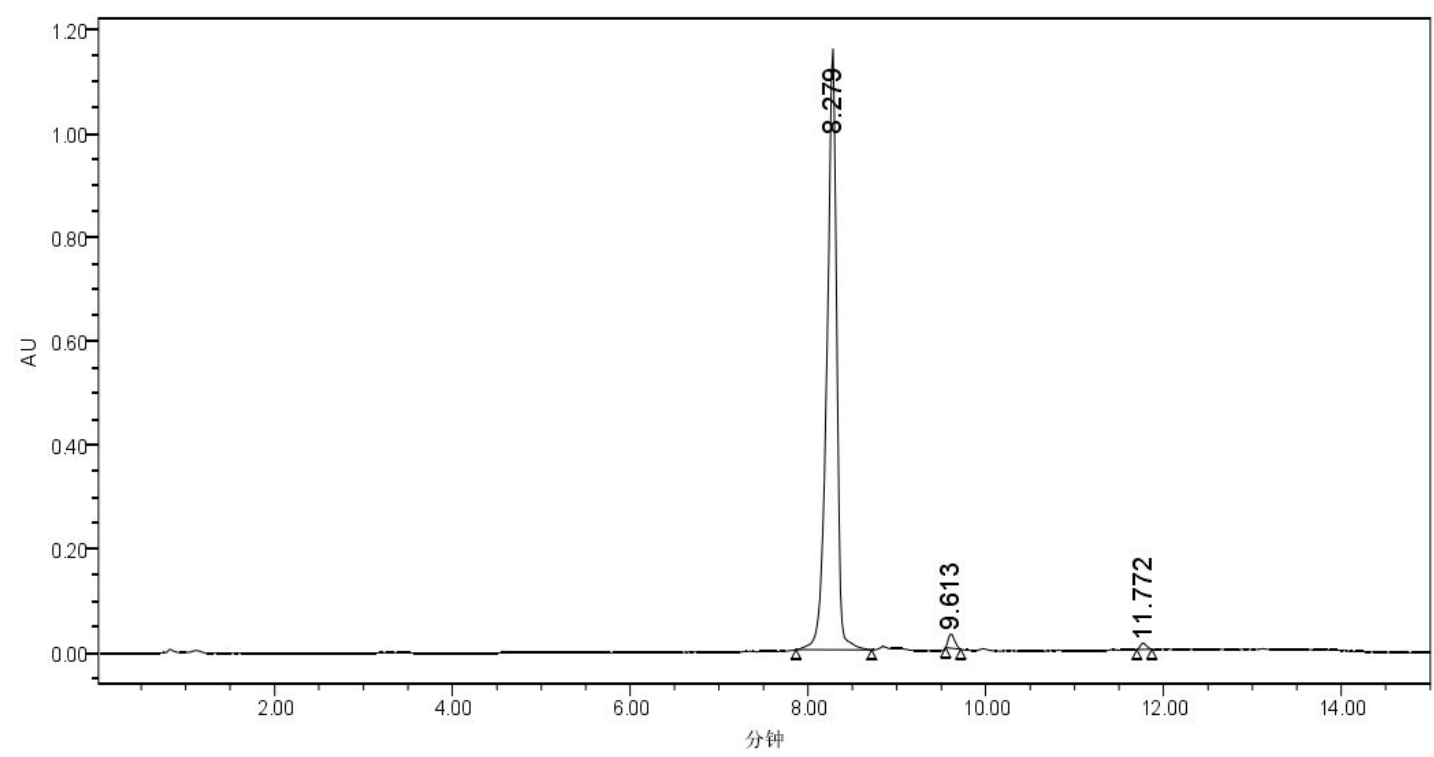


HPLC trace of $\mathbf{3 3}$

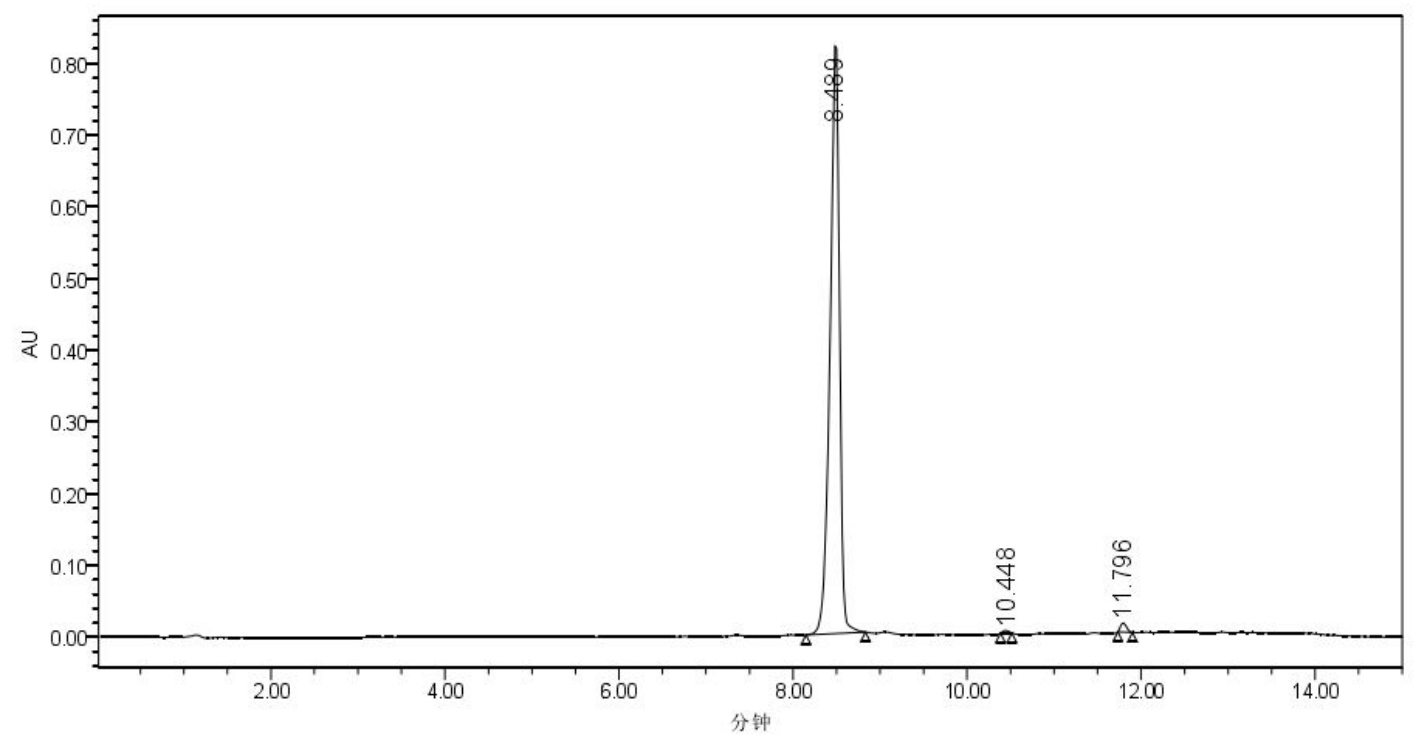

HPLC trace of $\mathbf{3 4}$

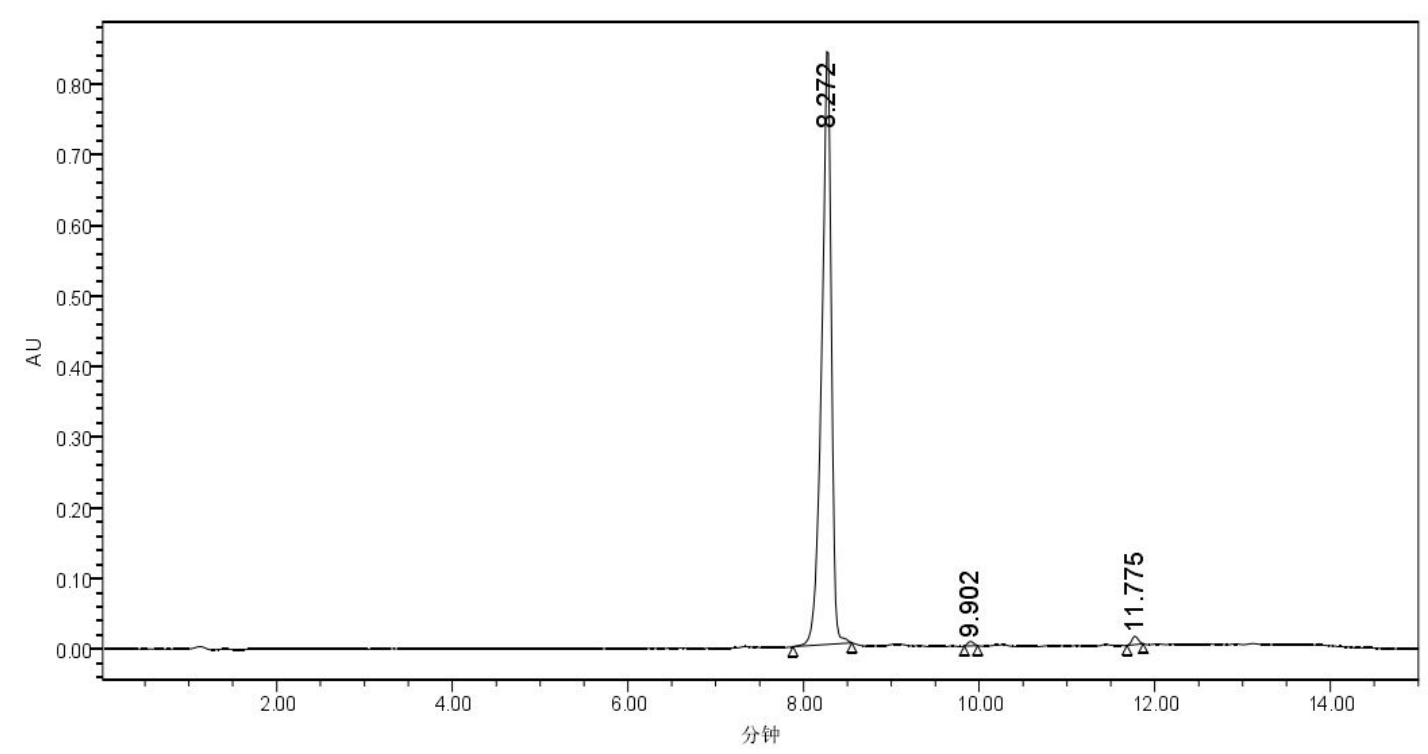


HPLC trace of $\mathbf{3 5}$

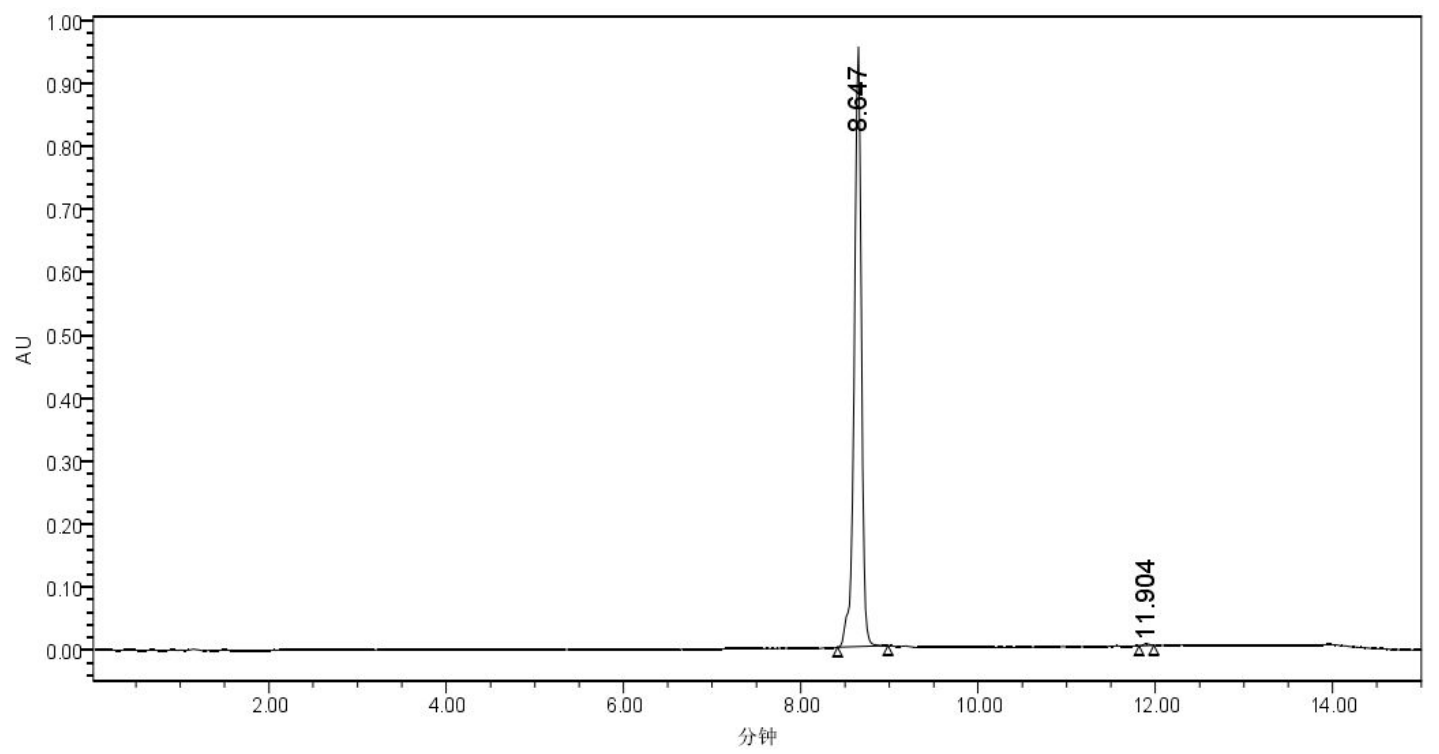

HPLC trace of $\mathbf{3 6}$

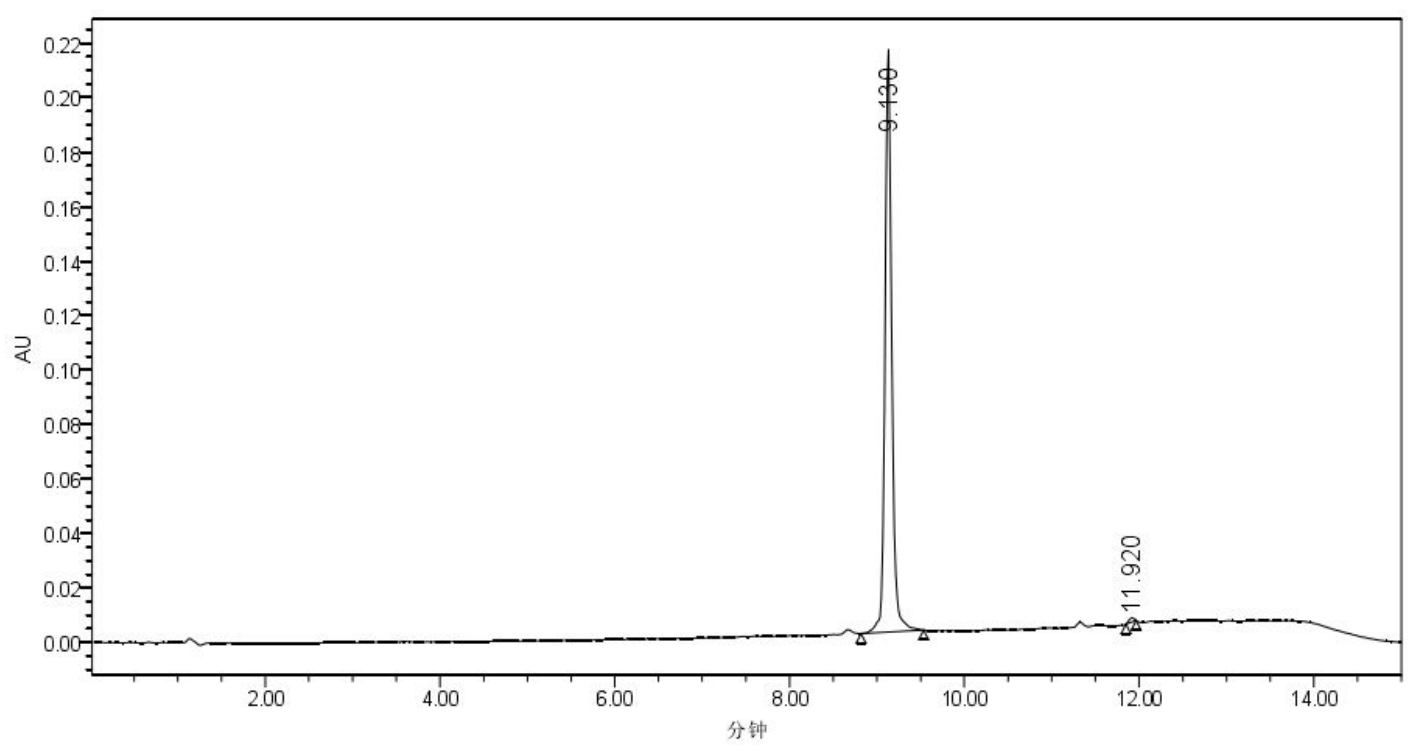


HPLC trace of $\mathbf{3 7}$

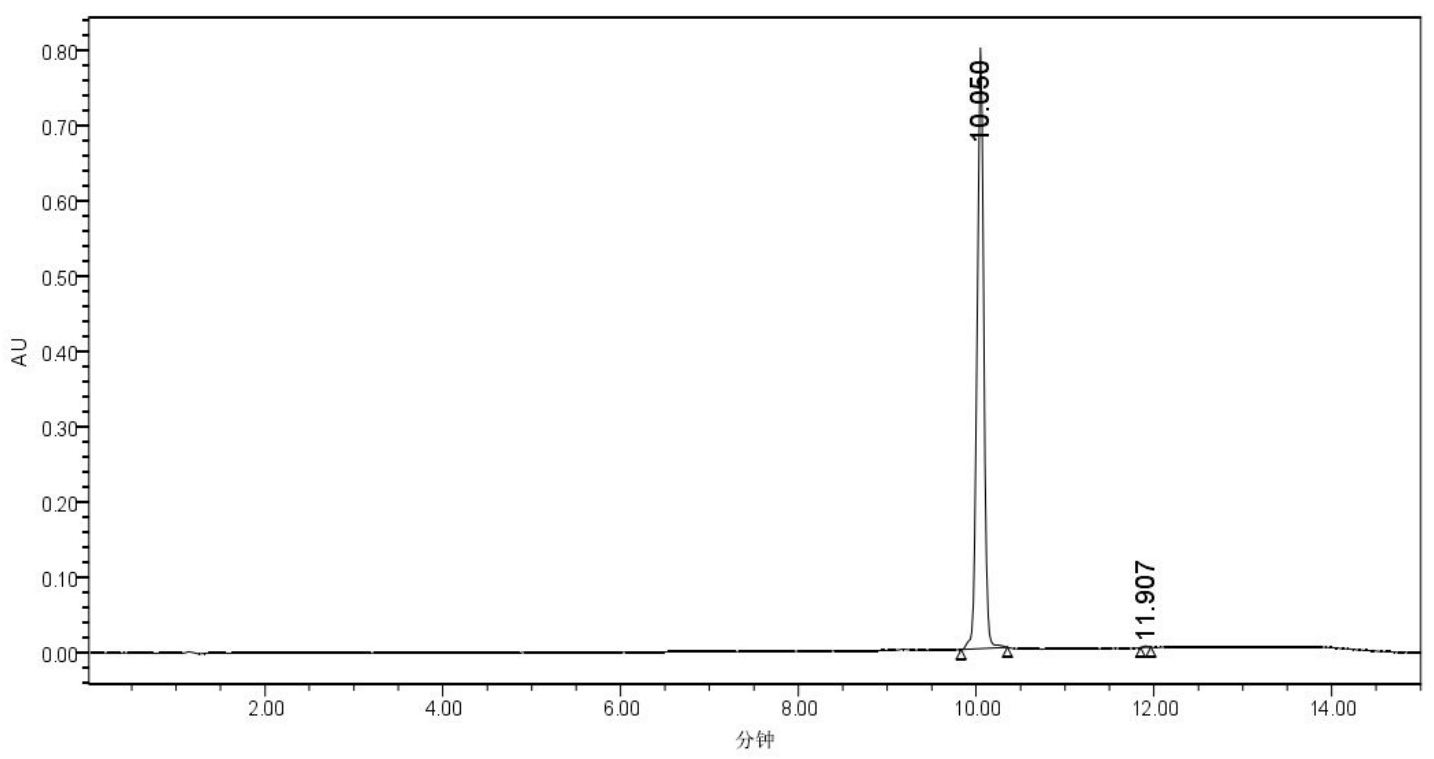

HPLC trace of $\mathbf{3 8}$

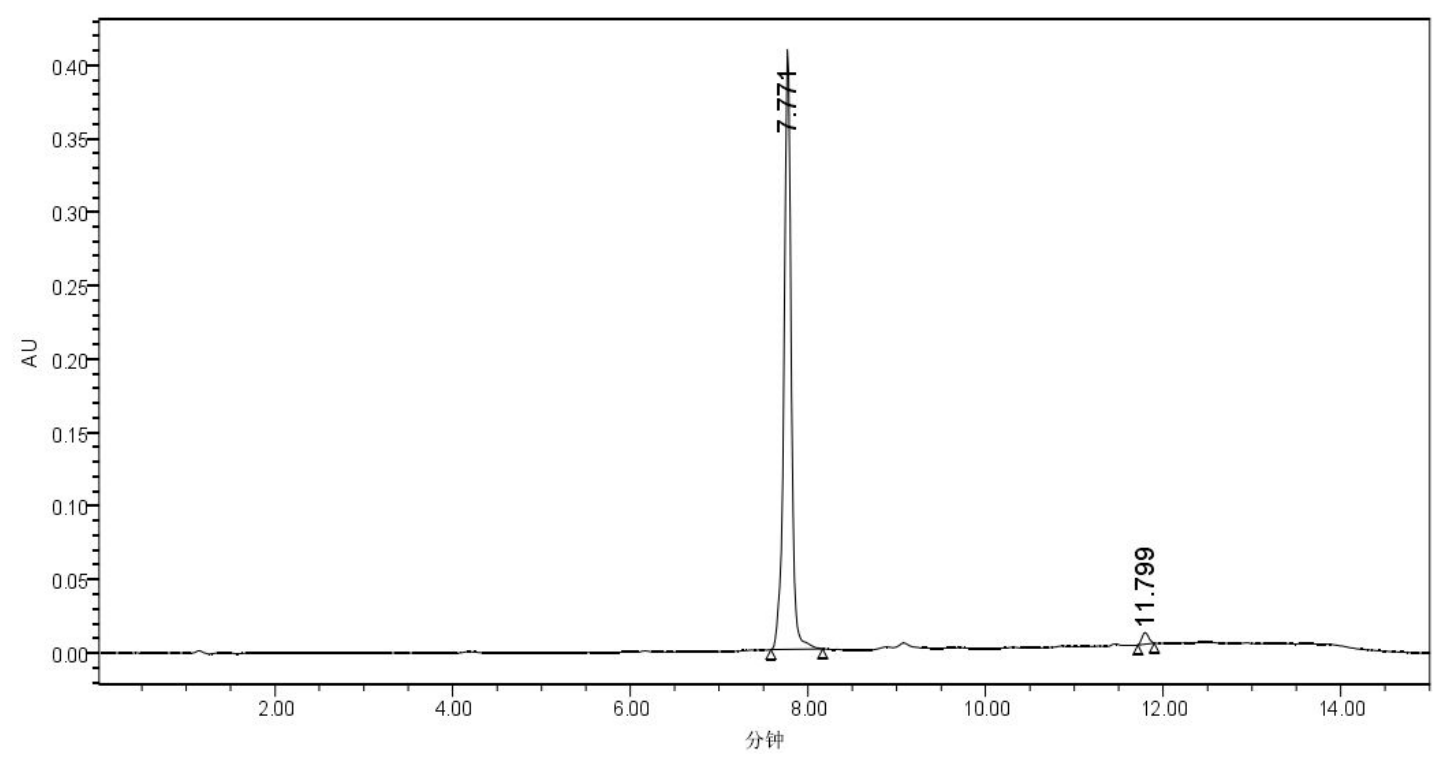


HPLC trace of $\mathbf{3 9}$

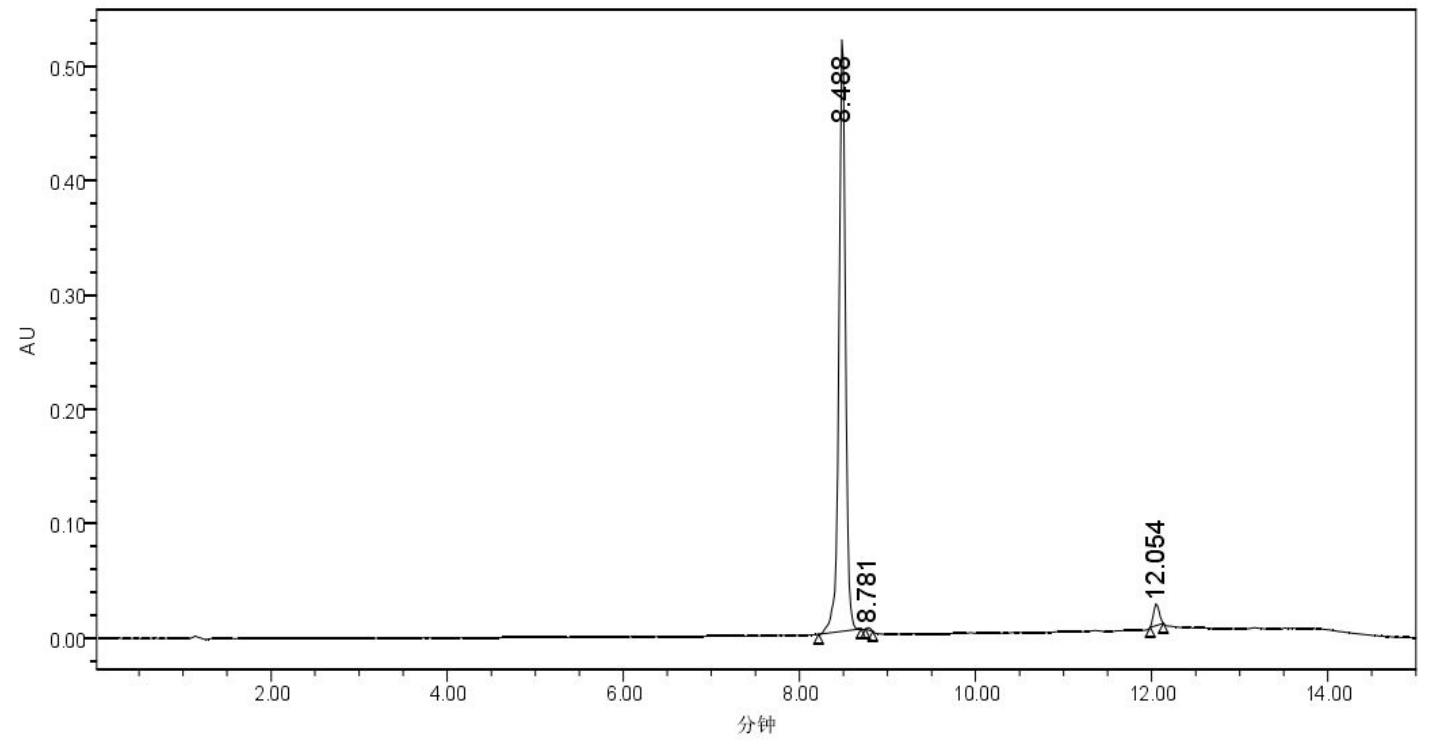

HPLC trace of $\mathbf{4 0}$

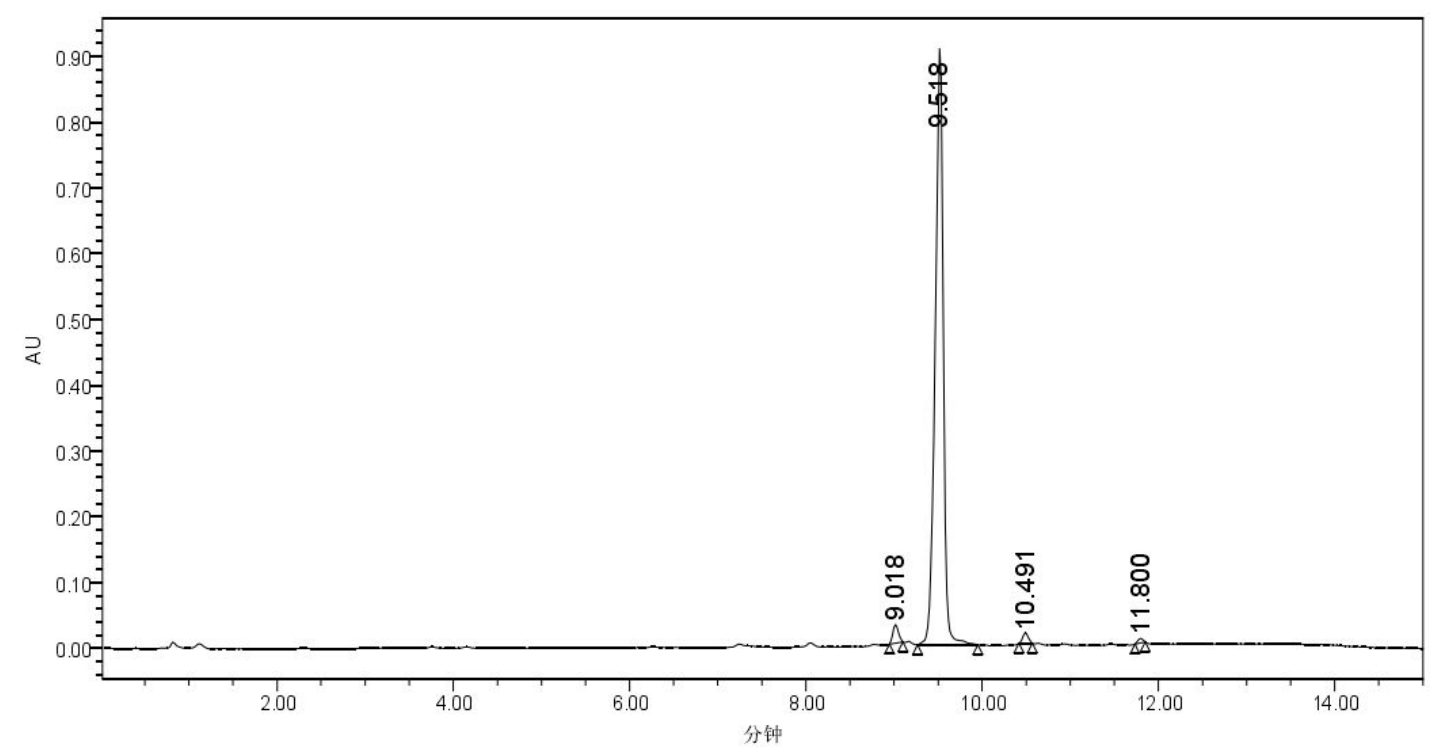


HPLC trace of $\mathbf{4 5}$

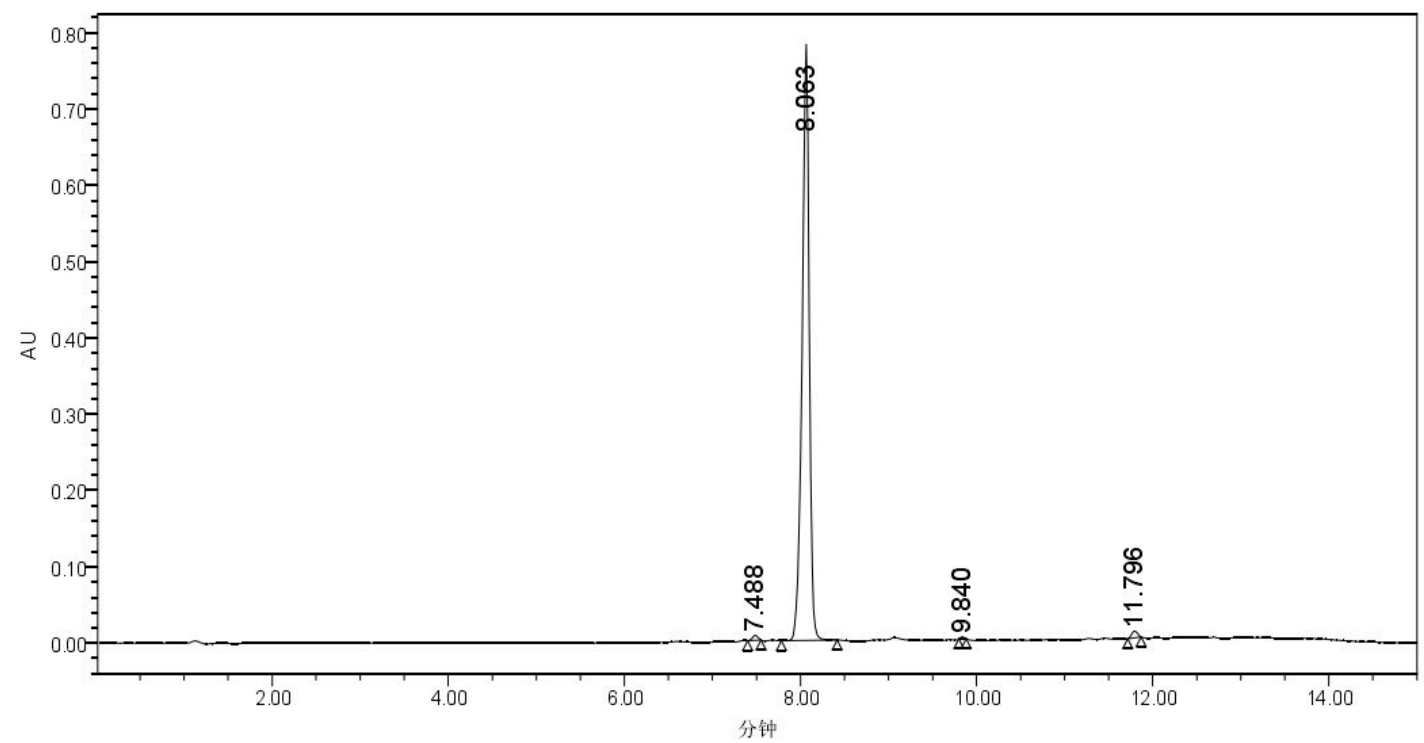

HPLC trace of 46

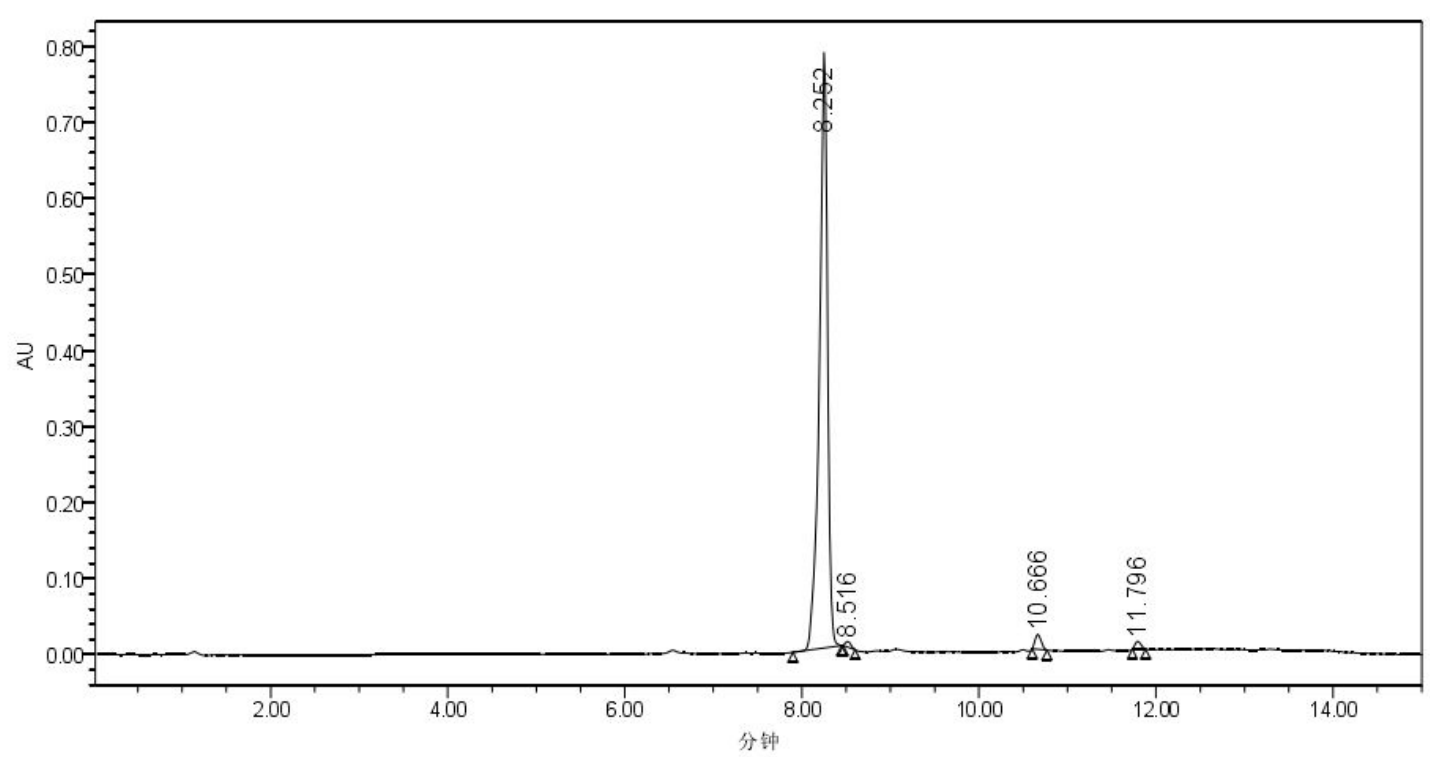


HPLC trace of $\mathbf{4 7}$

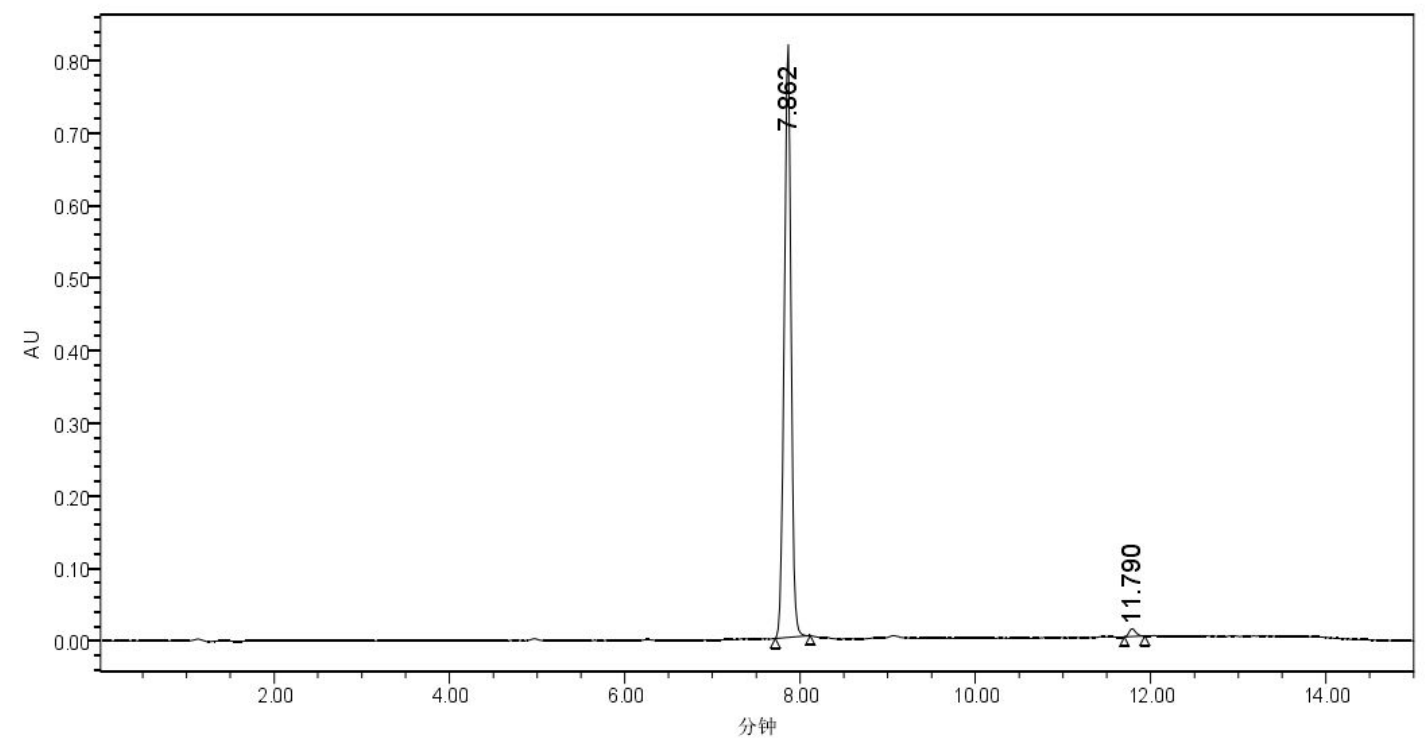

HPLC trace of $\mathbf{4 8}$

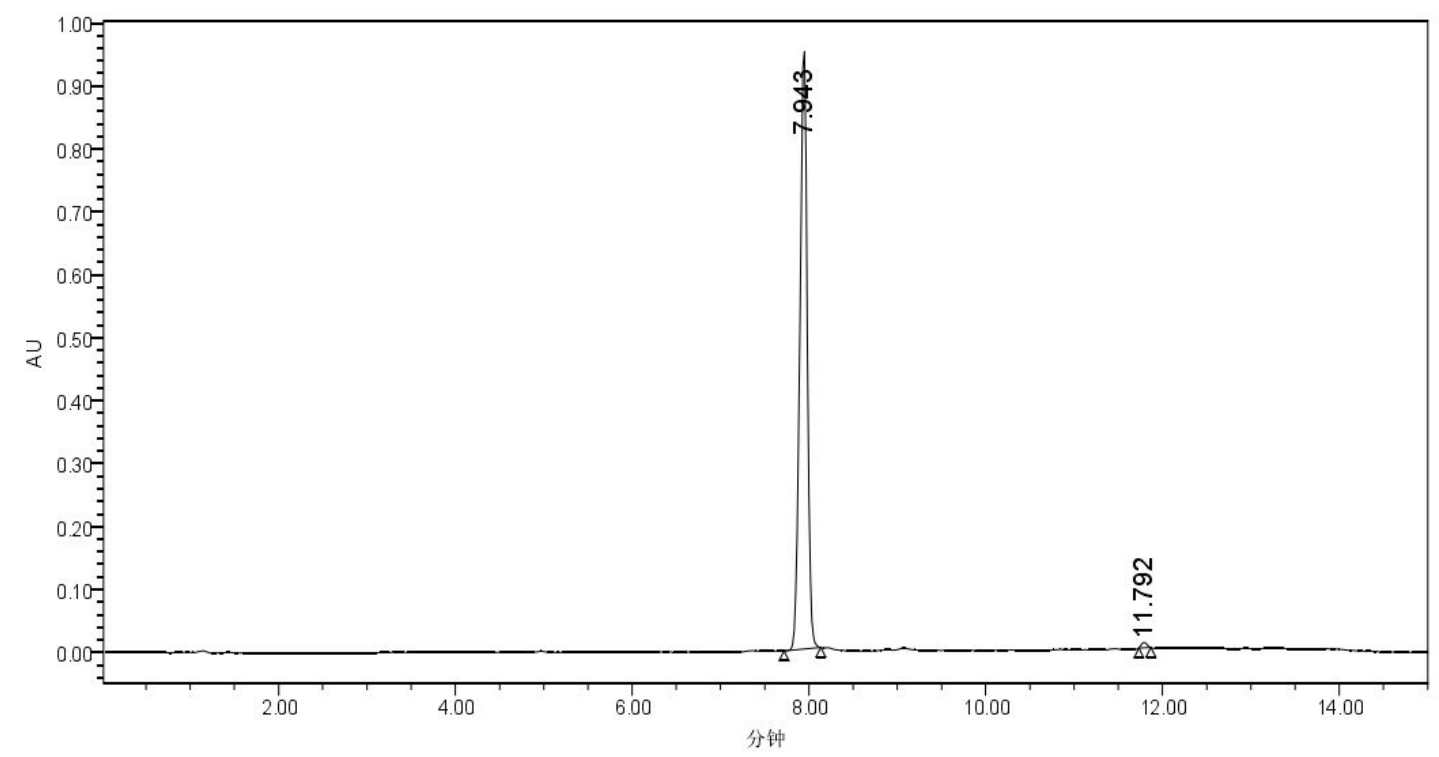


HPLC trace of $\mathbf{5 0}$

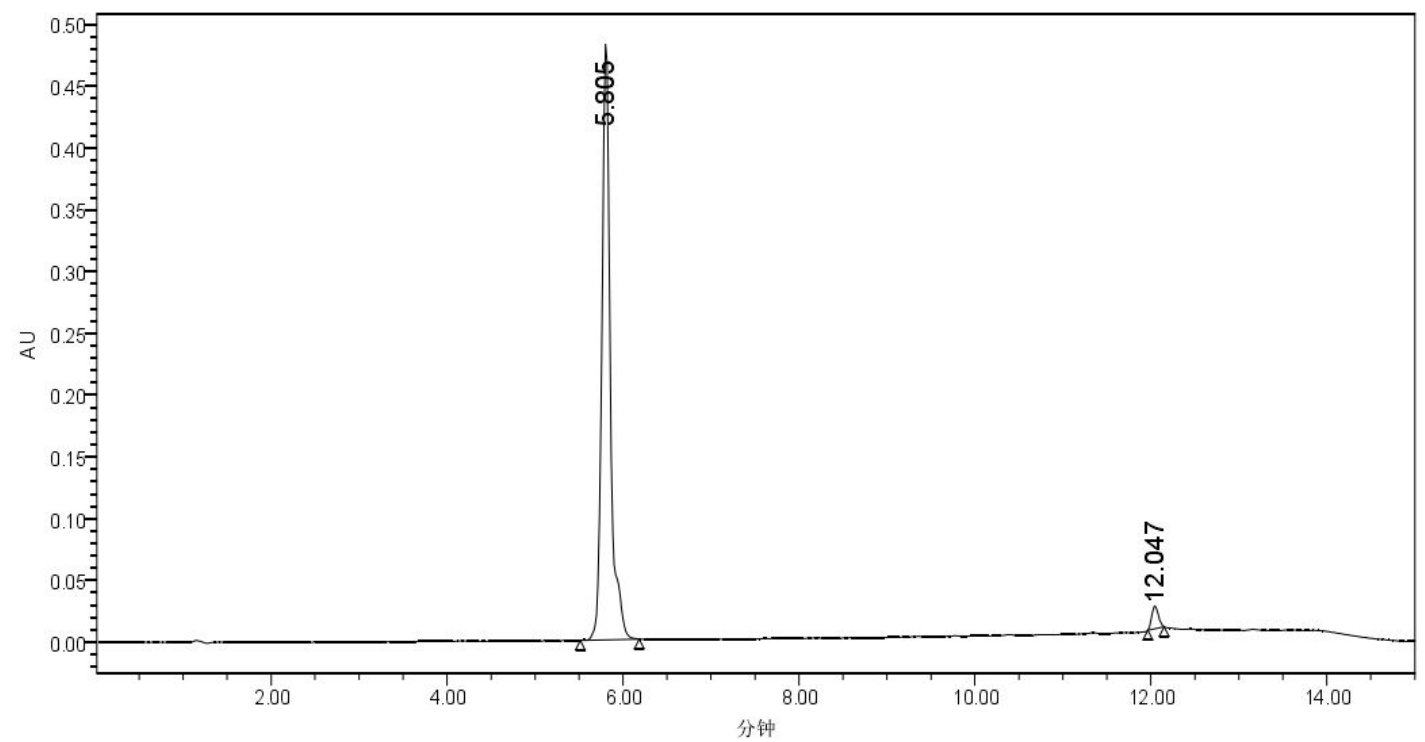

HPLC trace of $\mathbf{5 1}$

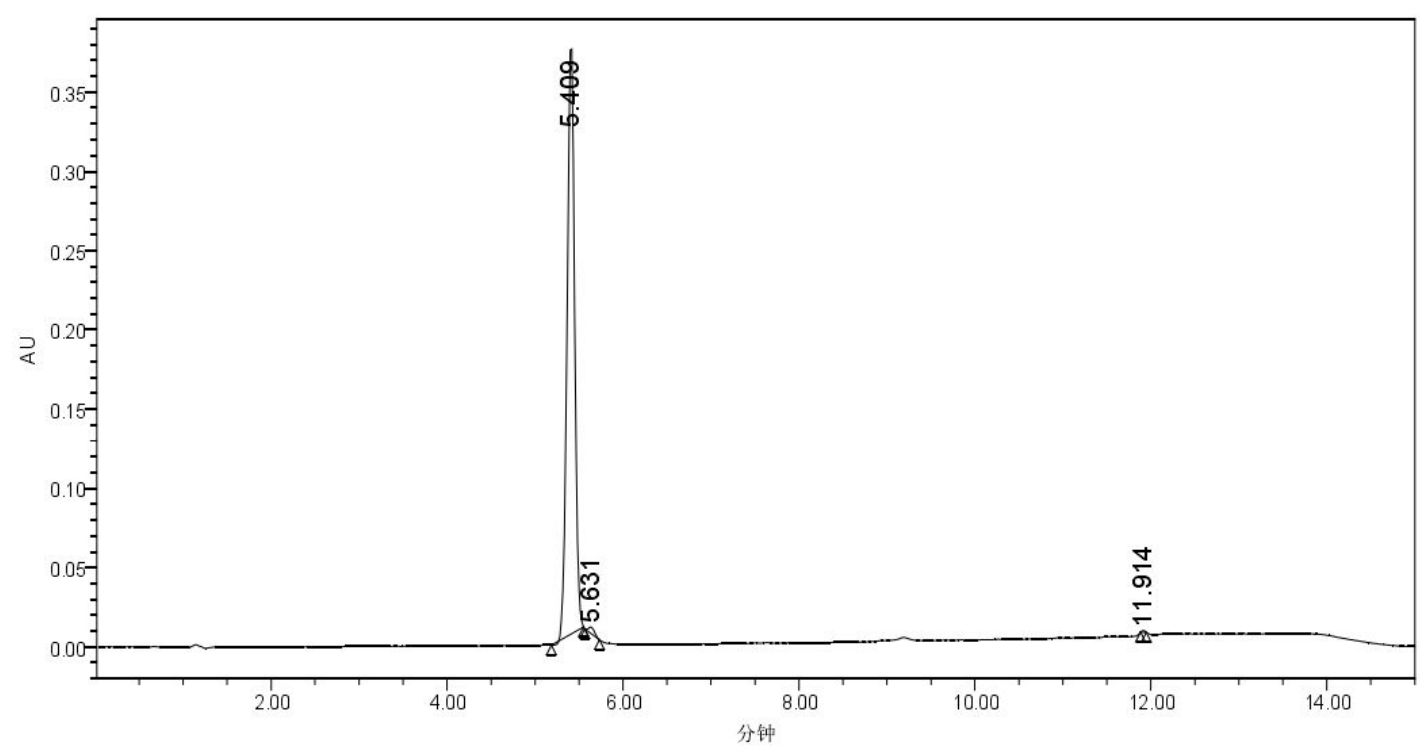


HPLC trace of $\mathbf{5 2}$

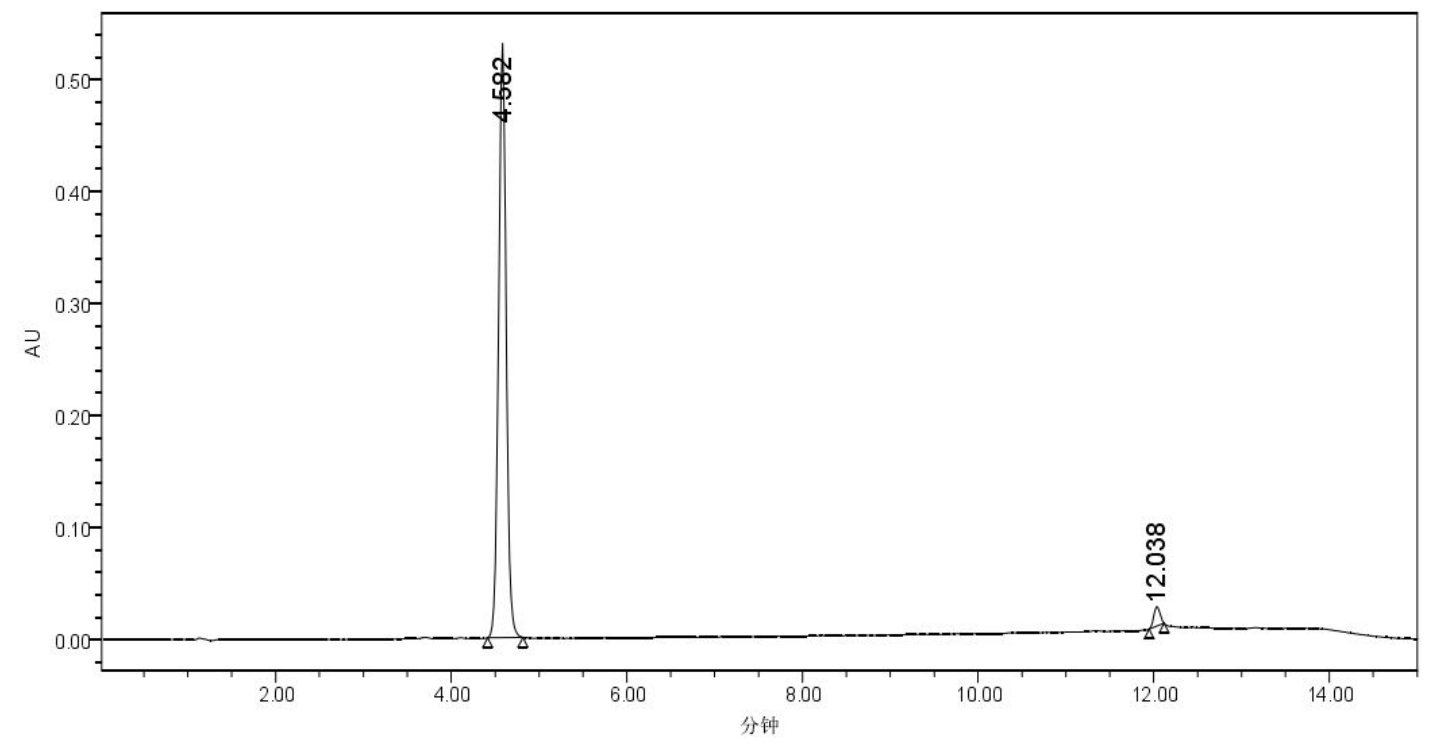

HPLC trace of $\mathbf{5 3}$

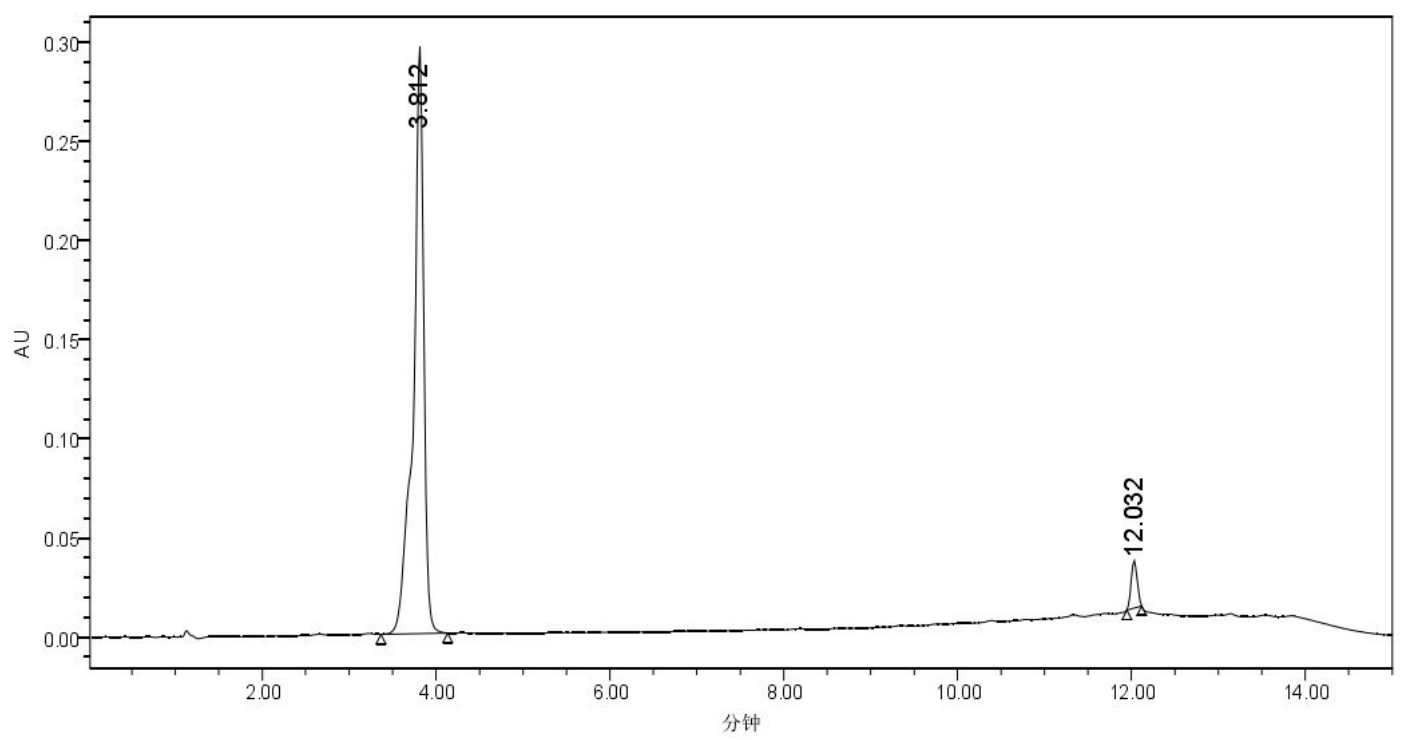


HPLC trace of $\mathbf{5 4}$

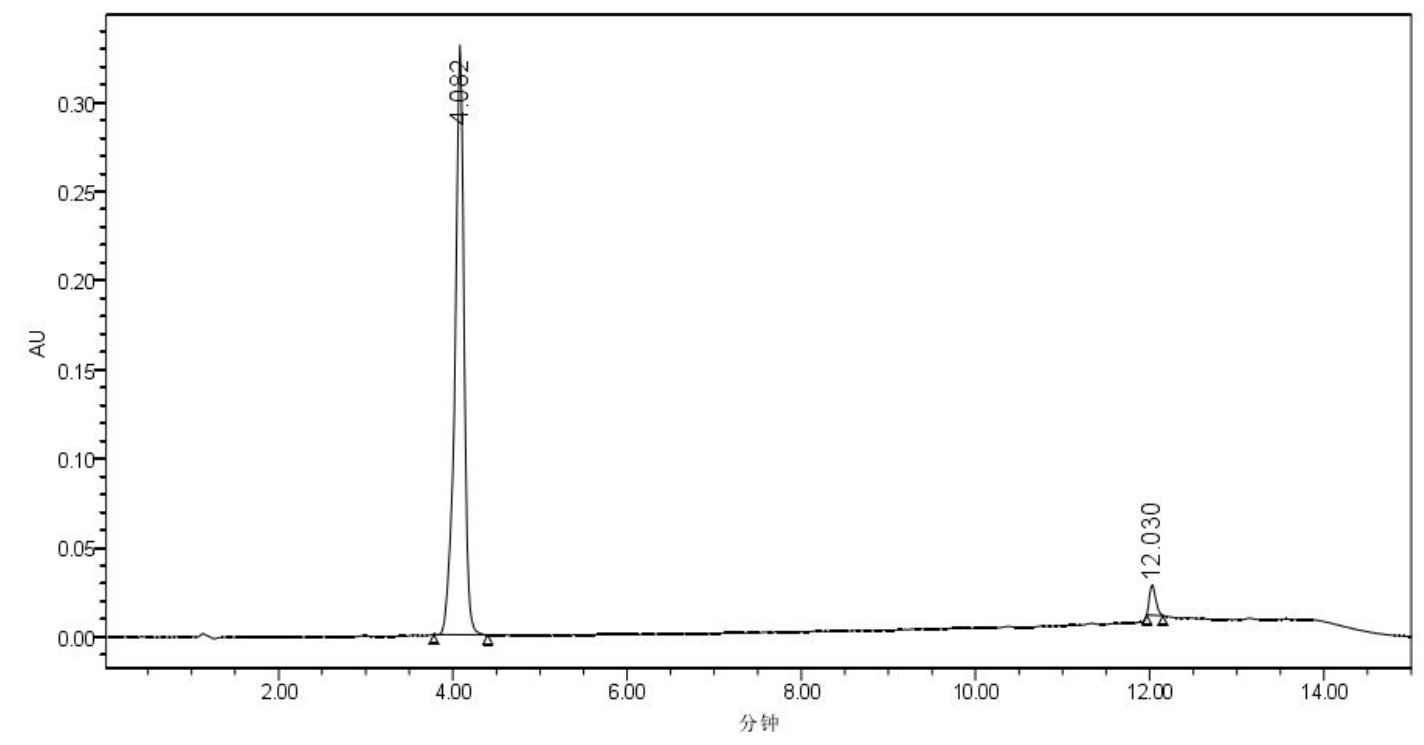

